\title{
Relationships of the Cambrian Protomonaxonida (Porifera)
}

\author{
Joseph P. Botting, Lucy A. Muir, and Jih-Pai Lin
}

\begin{abstract}
The Protomonaxonida consist of a heterogeneous group of early fossil sponges traditionally assigned to the demosponges. However, an affinity to the hexactinellid-like Reticulosa has also been suggested, and their relationships are potentially critical to understanding the origins of the extant sponge classes. In this paper, the relationships of the protomonaxonid sponges to each other and to other sponge groups have been reassessed, using previously described specimens as well as new material from the Burgess Shale of Canada and the Hetang Biota of South China. The sponges fall into two coherent groups, one consisting of taxa with long, mostly sub-longitudinal spicules, and the other with complex arrays composed of tracts of minute (millimetre-scale) monaxons, which grade into aspiculate taxa such as the Vauxiidae. Previous ideas relating the Protomonaxonida to extant demosponge lineages are supported in the case of the second group, whereas the first group confirms the view of derivation from a hexactinellid-like ancestor. Whether the two groups were directly related or evolved monaxonid spiculation in parallel is currently uncertain.
\end{abstract}

Joseph P. Botting. State Key Laboratory of Palaeobiology and Stratigraphy, Nanjing Institute of Geology and Palaeontology, Chinese Academy of Sciences, 39 East Beijing Road, Nanjing 210008, China acutipuerilis@yahoo.co.uk

Lucy A. Muir. State Key Laboratory of Palaeobiology and Stratigraphy, Nanjing Institute of Geology and Palaeontology, Chinese Academy of Sciences, 39 East Beijing Road, Nanjing 210008, China lucy@asoldasthehills.org

Jih-Pai Lin (corresponding author). State Key Laboratory of Palaeobiology and Stratigraphy, and Key Laboratory of Economic Stratigraphy and Palaeogeography, Nanjing Institute of Geology and Palaeontology, CAS, 39 East Beijing Road, Nanjing 210008, China jplin@nigpas.ac.cn

Keywords: Burgess Shale; Demospongiae; Hetang Biota; lithistid; sponge

\section{INTRODUCTION}

The exact relationships of the major groups (classes) of sponges have not yet been fully resolved, either by molecular phylogenetics (Philippe et al., 2009; Sperling et al., 2010) or by palaeontology (Finks et al., 2003; Botting and Butterfield, 2005). A major palaeontological problem is that it is difficult to relate the earliest presumed representatives of the classes to their extant descendents, with class stem groups being particularly difficult to recognise in Cambrian faunas. It has

PE Article Number: 16.2.9A

Copyright: Paleontological Society May 2013

Submission: 21 July 2012. Acceptance: 21 April 2013

Botting, Joseph P., Muir, Lucy A., and Lin,Jih-Pai. 2013. Relationships of the Cambrian Protomonaxonida (Porifera), Palaeontologia Electronica Vol. 16, Issue 2; 9A; 23p;

palaeo-electronica.org/content/2013/421-protomonaxonid-relationships 
sometimes been assumed that the class-level relationships of sponges are not possible to address using the fossil record, as spicules of demosponges and hexactinellids were until recently considered to have been derived independently (Reitner and Mehl, 1996), and hence the common ancestor would have been without spicules, and so was unlikely to be fossilised. Although extant demosponge and hexactinellid spicules share a fundamentally similar composition and structure, with opal-A deposition onto an axial filament, they differ in their symmetry (e.g., Bergquist, 1978; Brusca and Brusca, 2003) and axial filament symmetry (Reiswig, 1971), together with aspects of secretion mechanism (discussed by Uriz, 2006). However, even within demosponges there is a greater diversity of secretion mechanisms (Uriz, 2006) than had been previously appreciated, and the similarities between spicules in the two classes are now generally regarded as outweighing the differences, such that spicules within Silicea (= Demospongiae + Hexactinellida, excluding Homoscleromorpha) are very likely to be homologous (Sethmann and Wörheide, 2008; Sperling et al., 2010). The discovery of biminerallic spicules, containing both silica and calcite, in several groups of early sponges (Botting and Butterfield, 2005; Bengtson and Vinther, 2006; Botting et al., 2012) provides evidence that spicules are homologous even in calcareous and siliceous sponges. New information on the spicule structure of the hexactinellid-like sponge Cyathophycus (Botting and Muir, in press) further supports the notion that the separation of demosponges and hexactinellids occurred in an already spiculate group, and that this transition should therefore be preserved in the fossil record. Conversely, it implies that extinct stem-group lineages must be considered when interpreting the early fossil record, rather than simply comparing with the crown group classes.

The most comprehensive interpretations of sponge phylogeny based on the fossil record fall into two distinct schools: that of the German group including D. Mehl (later D. Janussen) and J. Reitner, and North American research based on the work of R.M. Finks and J.K. Rigby (summarised by Finks et al., 2003). Neither group has employed cladistic analyses, which in our opinion also would be premature for early Porifera (see Discussion). The most detailed phylogenies proposed are those of Reitner and Mehl (1996) and Mehl-Janussen (1999). Reitner and Mehl (1996) focussed on biological data; fossils were considered only as an indication of a deep (Precambrian) divergence of the sponge classes. They found Porifera to be monophyletic, with Hexactinellida as the earliestbranching group, followed by Calcarea, Homoscleromorpha, and Demospongiae. This topology is now contradicted by molecular work, implying that the characters used to define clades are at least in part unreliable.

The Cambrian fossil record of putative demosponges consists of the "Protomonaxonida" (Finks and Rigby, 2004a), keratose sponges (Vauxiidae) tentatively assigned to the Verongida (Rigby, 1986a), a few Middle Cambrian lithistids assigned to the extinct Anthaspidellidae (summarised by Pisera, 2006; Carrera and Botting, 2008), and a sparse record of isolated tetractine spicules with a very small number of articulated remains (Ivantsov et al., 2005). Tetractines (based on tetrahedral symmetry) are present in demosponges (but are probably derived; Borchiellini et al., 2004), and also in Homoscleromorpha and Calcarea, but this symmetry form is unknown (barring fortuitously aberrant spicules) in living or fossil hexactinellids. It is currently unclear to what extent tetractines evolved convergently, and to what extent they are homologous, so that their early record is of significant interest. Cambrian tetractine-based sponges are very poorly known, although their distinctive spicules occur earlier than demonstrable protomonaxonids (Bengtson et al., 1990), and there are diverse early Cambrian taxa including possible geodiid sterrasters (Gruber and Reitner, 1991; Reitner and Mehl, 1995). Putative records of demosponge remains from the Precambrian are either very ambiguous ( $\mathrm{Li}$ et al., 1998) or have not been fully described (Reitner and Wörheide, 2002), and therefore cannot be assessed.

The protomonaxonids dominate the sponge faunas of many of the Cambrian Burgess Shaletype deposits, but their origins and relationships are controversial. De Laubenfels (1955) attempted to integrate them into modern lineages (including Poecilosclerida, Haplosclerida, and Hadromerida), but our understanding of both modern and fossil sponges have changed significantly since that time. Some authors (Rigby, 1986a; Finks and Rigby, 2004b; Rigby and Collins, 2004) have considered effectively all protomonaxonids to be primitive demosponges, and to form a phylogenetically coherent (although presumably paraphyletic) lineage. Reitner and Wörheide (2002) also suggested definitive links between specific protomonaxonid and modern groups, including that the Choiidae (combined with the Halichondritidae) were ancestral to the axinellid-like Ordovician sponge Sacca- 
spongia (Finks, 1967; Mehl-Janussen, 1999) and were probably close to the modern Halichondriidae. Reitner and Wörheide (2002) regarded the vauxiids as stem-group "keratose" demosponges (but excluding Halisarcidae, and therefore representing a relatively derived position, within the crown group of keratosans as a whole). The problematic Saetaspongia (here considered to be more reticulosan-like, following Finks and Rigby, 2004a) was described as a demosponge of uncertain affinity.

In contrast, some authors (de Laubenfels, 1958; Reitner and Mehl, 1995; Debrenne and Reitner, 2001) have argued that at least the long-spiculed, semi-reticulate forms such as Leptomitus constitute a group of hexactinellids with originally hexactine-based spicules reduced to monaxons, citing modern groups such as the Rossellidae that include similarly monaxon-based skeletons. The finer-spiculed forms such as hazeliids have also been suggested to have been derived from the monaxon-based, inner skeletal layer seen in some reticulosan hexactinellids (Botting, 2003).

The few phylogenetic scenarios proposed for the internal relationships of protomonaxonids and their allies have been generally speculative and not tightly constrained, probably largely because of the limitations of the available data (particularly the discontinuous morphological range in known taxa). Mehl-Janussen (1999) provided a detailed discussion and proposed phylogram for Palaeozoic demosponges, including several named protomonaxonid groups. However, character transitions were not always specified, and several polychotomies were left unresolved. Some elements of her figure agree with our results, such as Hazelia being near to the basal anthaspidellids, and the keratosan sponges having secondarily lost spicules. Other aspects differ substantially from that presented below, particularly in the relationships of particular genera, which we have not been able to support. The main limitation of that scenario, however, is that most character transitions provided among protomonaxonids lead to single taxa. This makes it difficult to employ as a framework for discussion, especially as many protomonaxonid groups were omitted.

These views are contradicted in many respects by the phylogenies from North American workers, who have not, however, offered a character-based framework. Finks (2003) discussed the possible relationships of early demosponges, and also regarded the hazeliid architecture as being critical to the origin of several groups, such as the
Anthaspidellidae. He did not, however, discuss the large-spiculed protomonaxonids. These and all other protomonaxonids were included by Finks and Rigby (2004b) in an emended diagnosis of the Clavaxinellida that emphasised the possession of fibrous skeletons with abundant monaxial spicules. In contrast, Rigby and Collins (2004) provided a summary diagram, closely following Rigby (1986a), in which most Cambrian demosponges were loosely affiliated (although lineages not joined basally), but with little detailed justification for their arrangement. Leptomitids were considered to be basal to other protomonaxonids, but the authors did not provide a series of sequential character transitions, and the reasons for their topology are not obvious. In some cases, the text directly contradicts the figure, and neither presents a framework that can be easily used to accommodate (or be tested by) further discoveries.

These previous interpretations of protomonaxonid relationships have been based largely on the descriptions of Burgess Shale taxa by Walcott (1920), Rigby (1986a) and Rigby and Collins (2004), and the reconstructions provided in the latter two publications. Although the Chinese Cambrian faunas have also yielded protomonaxonids (e.g., Chen et al., 1989, 1990; Rigby and Hou, 1995), these have mostly either been the same genera as found in North America, or obviously closely related ones, and have so far provided little scope for revising interpretations of the group. This is now changing with the discovery of a diverse suite of basal, hexactine-bearing protomonaxonids (discussed below).

Phylogenetic relationships within unequivocal demosponges have also been problematic. Traditional palaeontological views of demosponge phylogeny (summarised by Reid, 1963) assumed that tetraxonid sponges were basal to other groups. This appears to have been largely a result of the assumed primitiveness of Homoscleromorpha, which include tetraxonid taxa; the Homoscleromorpha, however, are now typically regarded as being more closely allied to Calcarea than to demosponges based on molecular work (e.g., Borchiellini et al., 2004; Erpenbeck and Wörheide, 2007), and are therefore irrelevant to demosponge evolution. Finks (1967) questioned the primitive status of tetraxonids due to their late appearance in the fossil record, but this was based on very incomplete knowledge, and Cambrian tetraxons have been discovered subsequently (Van Kempen, 1985; Bengtson et al., 1990). Finks (1967) did not suggest any phylogenetic relationships within Proto- 
monaxonida, but regarded the group as a whole to be ancestral to a wide range of demosponge lineages, at least some of them directly.

Reid $(1968,1970)$ modified his earlier views after intensive study of additional characters such as microscleres and larval form, and suggested parallel monaxonid and tetraxonid lineages with unknown relationships to each other. This assumed the existence of microspiculate precursors that had not been preserved, and also suggested some degree of separation of homoscleromorphs from other demosponges. This framework emphasises the problems with recognising modern demosponge lineages in early fossils, as the most dominant putative demosponges in Cambrian rocks are protomonaxonids, suggesting that recognisable crown-group lineages evolved somewhat later. However, studies using molecular clock data have indicated that crowngroup demosponges should have evolved by around $700 \mathrm{Ma}$ (Sperling et al., 2010; Erwin et al., 2011). Problems with the limited fossil record are particularly acute concerning microscleres, which would provide constraints on interpretation of putative demosponges, but are rarely preserved. However, a diverse fauna of apparently modern microscleres is known from the early Ordovician (Kozur et al., 1996), implying that many modern lineages already existed at that time but have not been recognised.

The new interpretations of internal and wider relationships presented here are based on new taxa from the early Cambrian Hetang Biota of Anhui, China (Xiao et al., 2005), combined with a re-examination of middle Cambrian Burgess Shale material held in the Royal Ontario Museum (Toronto, Canada). Features that are important in interpreting protomonaxonid relationships are the size and morphology of spicules, their local arrangement and broader three-dimensional architecture, and the organisation of additional skeletal materials in some groups. Skeletal architecture is considered here to be the most reliable feature to use in classification, even though this differs from current practice (Finks and Rigby, 2004b). More detailed imaging than in earlier studies has allowed the description of aspects of skeletal architecture that have not previously been noted, while additional material has allowed a refined interpretation of the structure of certain taxa. These observations have resulted in the protomonaxonids being divided into two major groups, which may or may not be closely related. The evolutionary directionality of one of these groupings is polarised by refer- ence to modern demosponges and the other by reference to new Early Cambrian hexactinellid-like sponges from the Hetang Biota, South China.

The two groups are discussed below, each subdivided into a morphological continuum of family-level sub-groups. These groups should be regarded as informal at present, but lists of included genera are given as an aid to understanding.

\section{MATERIALS AND METHODS}

This study is based on specimens collected by JPB, LAM, JPL, and others from the Hetang Formation of Anhui, South China (TommotianAtdabanian, Xidi brick Pit, $29.52^{\circ} \mathrm{N} ; 118.03^{\circ} \mathrm{E}$; see Xiao et al., 2005 for stratigraphy), and deposited in the Nanjing Institute of Geology and Palaeontology (NIGP155891-7). Burgess Shale material (Cambrian stage 5, British Columbia - see Rigby and Collins, 2004 for detailed locality information) is housed in the Royal Ontario Museum, Toronto (ROM). Specimens were imaged via a Nikon SMZ1500 stereomicroscope with attached LV-TV camera system (ROM) and with a Nikon D80 camera with Sigma $105 \mathrm{~mm}$ macro lens.

\section{RESULTS}

Based on the detailed observations and discussions below, we divide the protomonaxonids into two major groups. The first group contains taxa with long spicules, mostly arranged sub-longitudinally. This group includes basal protomonaxonids and leptomitids, hamptoniids, and most choiids. The second group consists of sponges with minute monaxons arranged in complex arrays, such as hazeliids, and forms a continuum with aspiculate taxa, e.g., Vauxia. In this manuscript, "basal" refers to a paraphyletic grade that probably includes the origins of early-branching clades.

Restudy of material in the Royal Ontario Museum has shown that the Takakkawiidae, traditionally considered to be protomonaxonids, are a distinct group of reticulosan sponges (Botting, 2012), and they are not considered further here.

\section{Group One Protomonaxonids}

The sponges included here are characterised by a dominantly longitudinal skeleton of coarse monaxons, often several centimetres in length, and at least some spicules a minimum of $5 \mathrm{~mm}$ long. In some cases there are additional transverse monaxons and/or hexactine-based spicules, but longitudinal monaxons are a unifying feature. The 
morphology of the sponges is simple, with axial symmetry; however, they show a wide range in expansion rate, from cylindrical to effectively discoidal.

The taxa included in this group are those referred to here as basal protomonaxonids, and the families Leptomitidae (including taxa previously referred to Wapkiidae), Hamptoniidae, 'Choiidae,' and Halichondritidae-Piraniidae.

Basal Protomonaxonids. Conical to elongate taxa with a thin wall consisting of a thatch of sublongitudinal or sub-helical monaxons, combined with an irregular array of hexactine-based spicules. Hexactines are often (but not always) short-rayed and with irregular inter-ray angles. Where monaxons are regularly sub-helical in orientation (righthanded helix, when looking upwards along the axis), they also tend to be more sparsely distributed, and hexactine-based spicules are less abundant. A subsidiary lineage within this group exaggerated a dense array of highly modified, short-rayed hexactines, to the reduction and eventual exclusion of monaxons.

Hyalosinica archaica Mehl and Reitner in Steiner et al., 1993 is the only previously described example of this group, which includes dominantly monaxonid sponges with additional hexactinebased spicules. Although originally described as a probable root tuft with associated short-rayed hexactines, the sparse and semi-regular spiculation is suggestive instead of a thin-walled construction. This is confirmed by new specimens from the Hetang Biota (Figure 1), which include both Hyalosinica (Figure 1.1-1.2) and other forms with much less regular architecture (new genus B, Figure 1.3); all show associated hexactine spicules, which are commonly small and short-rayed (Figure 1.2, 1,5). In some cases, the monaxons are absent, leaving a dense mass of tiny hexactines or subspheroidal spicules forming the body wall (new genus $A$, Figure 1.4-1.5).

It is unclear whether the ancestral condition of this group consisted of a regular arrangement, with sparse, helically-disposed monaxons as in Hyalosinica, or possessed a dense, structureless thatch (e.g., Figure 1.6). Examples of both types are known with hexactines and broadly longitudinal monaxons. One conical species from the Hetang Biota shows a small number of more typical, thinrayed hexactines amongst a sparse monaxonbased skeleton that resembles Hyalosinica in density, but with less regularity (Figure 1.7-1.8). Certain flattened forms resembling Choiaella may also be referable to this group (discussed with Choiidae, below).

Leptomitidae. Conical-cylindrical sponges with a thin wall composed of large longitudinal monaxons (normally clustered into narrow tracts) and fine, sub-transverse monaxons (clustered into tracts, or separated) that appear to constitute an inner layer. Plumose arrays are present in the walls of some taxa (e.g., Wapkia), with transverse tracts deflecting downwards into localised sub-vertical tracts. The basal region shows a short, linear skeletal nucleation centre, which is possibly plesiomorphic for Group 1 protomonaxonids.

The genus Wapkia, previously referred to the monogeneric family Wapkiidae, is considered to belong in the Leptomitidae. Leptomitus, Leptomitella, and Paraleptomitella are also assigned to this group.

The phylogenetic reconstruction of protomonaxonids given by Rigby and Collins (2004) shows a loosely affiliated array of groups with the Leptomitidae being basal, but the absence of hexactines in leptomitids implies that they are secondarily derived from the forms discussed above. Rather than the irregular thatch-like architecture seen in Hamptoniidae and allies (discussed below), the Leptomitidae all possess a discrete transverse (strictly, low-angle helical in at least some taxa) skeletal complement, combined in most cases with bundling of the vertical monaxons (Figure 2.1, 2.3). These regular aspects of the architecture are likely to be synapomorphies of the family, although it is possible that they evolved from a basal protomonaxonid with more ordered architecture. Such architectural organisation is seen in undescribed sponges from the Burgess Shale (JPB personal observation) and the Fezouata Biota (Van Roy et al. 2010; JPB personal observation) faunas, where there are cylindrical sponges that are chaotically deformed but consisted of a thin wall of fine, exclusively longitudinal monaxons, apparently without transverse spicules (Figure 2.6).

The precise form of any intermediates between leptomitids and basal protomonaxonids is unknown. However, the specimen referred to Paraleptomitella? sp. by Zhao et al. (1999, plate 1, figure 7) possessed spicules that were largely parallel to each other, and oblique to the sponge axis. There is also an indication of opposing oblique spicules, and perhaps even some that are loosely transverse. Rotation of such an array could lead rapidly to true leptomitid architecture, and this sponge may therefore represent an intermediate 

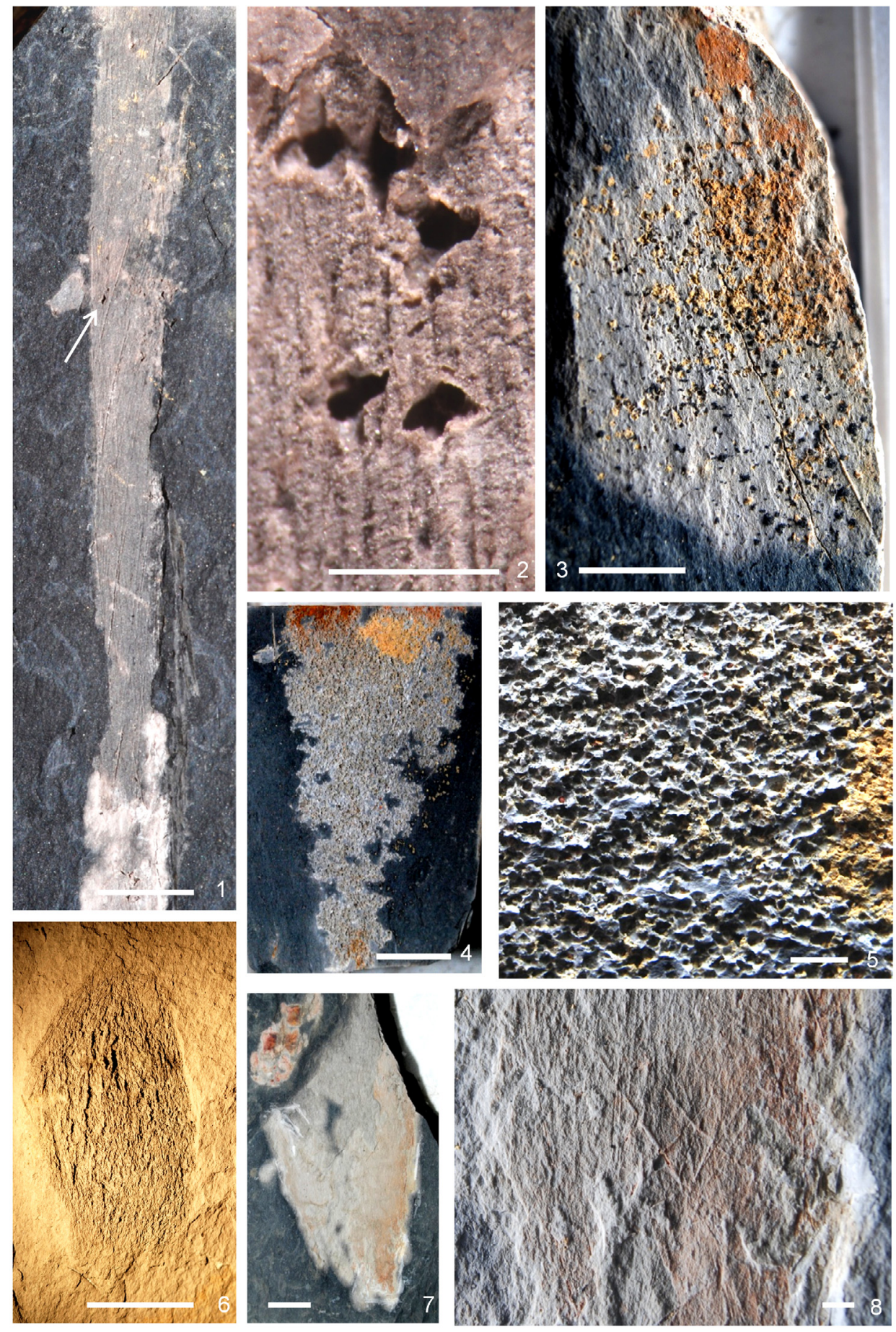

FIGURE 1. Basal protomonaxonids and a primitive hamptoniid from the early Cambrian Hetang Biota, South China. 1-2, NIGP154828 Hyalosinica sp.; 1, overall view with examples of hexactines arrowed; 2, magnification of hexactines in central part of (1); 3, NIGP155891 apparently undescribed genus (new genus B) with mass of minute, inflated and short-rayed hexactines (visible as tiny shadowed cavities) amongst irregularly-arranged, fine monaxons; 4-5, NIGP155892 undescribed genus (new genus A) with dense wall of minute, inflated-rayed hexactines and no monaxons; 4, overall view showing body form; 5 , detail showing mass of minute, short-rayed hexactines preserved as external moulds; 6, NIGP155893 probably undescribed genus (new genus C) with irregular, dense array of sublongitudinal monaxons but lacking hexactine-based spicules, interpreted as a primitive hamptoniid-like sponge due to the lack of hexactine-based spicules; 7-8, NIGP155894 probably undescribed genus with conical body wall containing mostly diagonally-oriented monaxons, and non-inflated hexactine-based spicules. Scale bars equal: $1,3: 5$ $\mathrm{mm} ; 2,5,8: 1 \mathrm{~mm} ; 4,6-7: 10 \mathrm{~mm}$. 

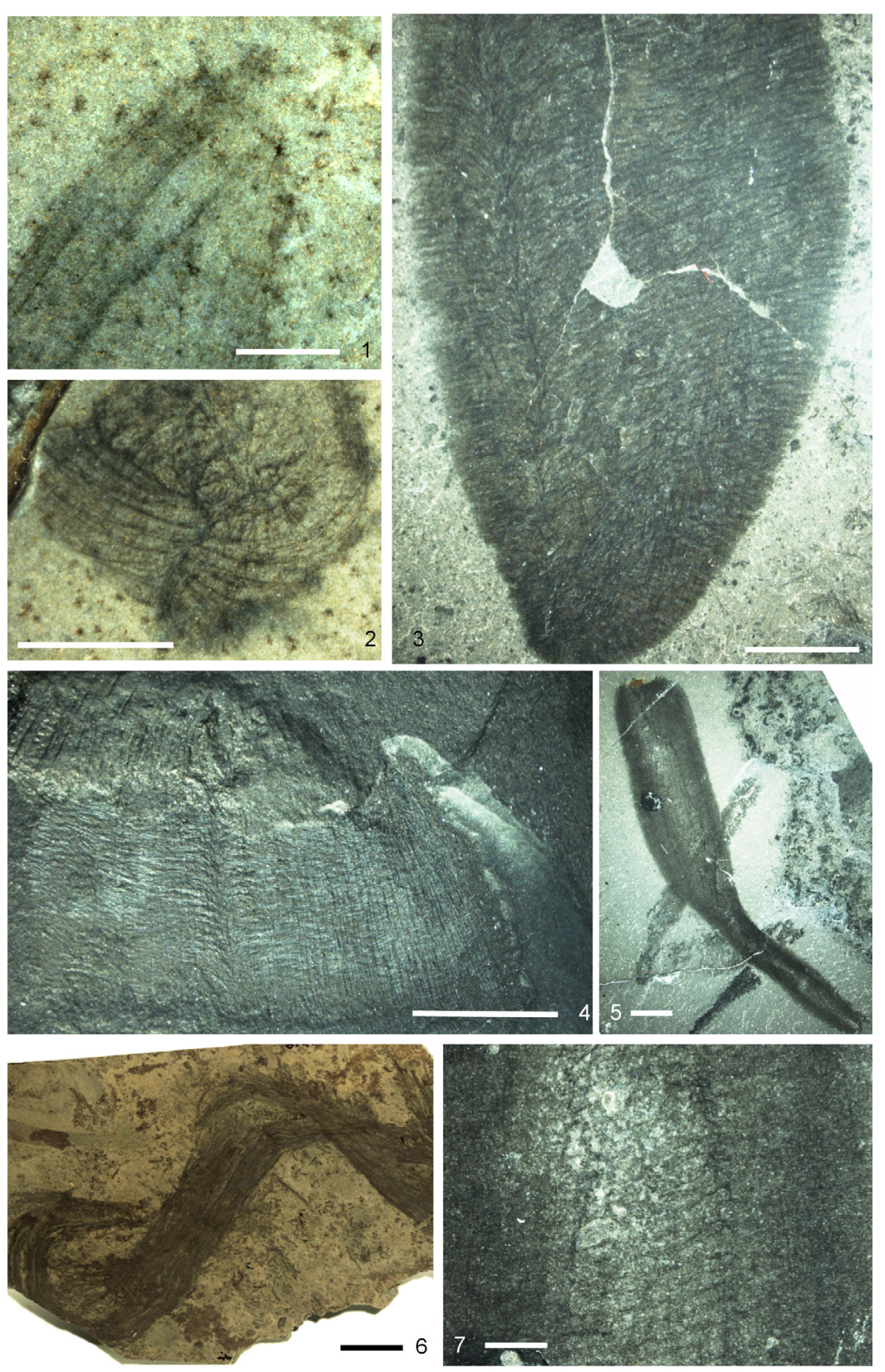

FIGURE 2. Leptomitidae, from the Burgess Shale (middle Cambrian, Canada). 1, 3 Leptomitus lineatus ROM 53558; 1 , apex of sponge showing longitudinal monaxon bundles converging towards narrowed osculum, and short transverse monaxons; 3, basal region with linear skeletal nucleation centre; 2, 4 Wapkia elongata; 2, ROM53549, showing fundamental architecture of longitudinal spicules with prominent development of transverse monaxon bundles, distorted into plumose array in left half; 4, ROM 53544, apical region of holotype showing skeletal architecture. 5, 7, ROM6I9I5, probably undescribed leptomitid-like sponge with thick wall and complex architecture from Burgess Shale locality S7; 6, ROM6I9I0, undescribed protomonaxonid from the Burgess Shale locality S7; previously named as Leptomitus but lacks transverse spicules (photograph: J.-B. Caron, ROM). 1-3, 5, 7 photographed under crossed polarisers, with high-angle illumination; 4 photographed with low-angle illumination. Scale bars equal: 1, 7: $1 \mathrm{~mm} ; 2-$ 5: $5 \mathrm{~mm} ; 6: 50 \mathrm{~mm}]$. 
morphology. Alternatively, an Ordovician sponge (Botting and Zhang, 2013) suggests that the Leptomitidae were derived from a related, but slightly separated branch of hexactine-bearing sponges that possessed both longitudinal and transverse monaxons, and also heteractine (pentaradiate and triradiate) spicules. The precise origin of this family therefore remains uncertain, and they may originate from a deep division within the protomonaxonids, or from a separate region of either the poriferan or a class-level stem group.

Within the Leptomitidae, genera are primarily separated based on the degree of spicule bundling (particularly among horizontal spicules). There is also, with the addition of Wapkia Walcott, 1920, a component of apparently plumose architecture in the wall (Figure 2.2, 2.4); this is also seen in, for example, the holotype of Leptomitus undulatus Rigby and Collins, 2004, but is better developed in Wapkia. The plumose architecture occurs entirely within the thin wall in the type specimens of the Wapkia species, and is effectively a two-dimensional divergent plume of monaxons, bundles from which curve towards the horizontal to become the transverse spicule bundles. This localised plumose array is the only significant difference of Wapkia from Leptomitella, and even in the holotype of Leptomitella metta there is an incipient plume developed (Rigby, 1983). Other superficially similar taxa have previously been included in descriptions of Wapkia (e.g., Rigby and Collins, 2004, plate 8, figure 1), but the structures of these are substantially more complicated. Various undescribed specimens of apparently related but thick-walled sponges are also represented in the Royal Ontario Museum collections (e.g., Figure 2.5, 2.7); this complex requires a dedicated study to unravel their structures and relationships, but we note that some of the smaller taxa possessed small monaxons arranged in a partly radial and semi-reticulate architecture, and therefore show some similarities to the Hazeliidae (below).

Hamptoniidae and 'Choiidae'. Conical to bowlshaped (possibly globose) and open conical to flattened sponges with irregular, dense longitudinal spiculation of large monaxons that are not strictly parallel. Monaxons are in some cases segregated into two distinct size classes, the largest often projecting from the wall apex; majority of spicules forming a single size continuum.

Most taxa traditionally assigned to the Choiidae are included here, as they are structurally identical with Hamptonia; this is most obvious in Choiaella, which is virtually indistinguishable from young specimens of Hamptonia. The group excludes taxa in which the larger spicules have developed into prostalia with a thick outer organic layer and an open base (Halichondritidae-Piraniidae, discussed below). Genera included in this group are Choia, Choiaella, Hamptonia, and Allantospongia.

The currently monogeneric Hamptoniidae contain structurally simple sponges, with a thin, bowl-shaped wall of loosely longitudinal monaxons (Figure 3.1). This arrangement resembles that of Halichondrites (see below), but differs in that most spicules do not project from the body, or lie almost flat against it. Specific similarities include the possession of bimodal spicules (although less pronounced), with the development of enlarged monaxons amongst the extremely dense sub-longitudinal thatch of smaller monaxons. Hamptonia bowerbanki Walcott, 1920 also shares a specific feature seen in Leptomitidae in the possession of a linear-plumose skeletal nucleation centre, a feature not known in halichondritids and piraniids. Given the apparently fundamental separation of the regular, spaced-skeleton architecture of the leptomitids, this type of nucleation centre must be assumed to be a primitive feature of growth in protomonaxonids.

Juvenile specimens of the hemispherical Hamptonia bowerbanki are nearly flat, discoidal sponges (Rigby and Collins, 2004). This makes them difficult to separate from Choiaella, except that the latter lacks bimodally differentiated spicules. The exaggeration of the larger spicules among the bimodal array of a juvenile Hamptonia would lead immediately to the forms closely resembling Choia (Figure 3.2-3.3), and such a generic transformation could have resulted rapidly from simple heterochronic changes combined with exaggeration of an already visible distinction between spicule types. The lack of any enlarged spicules in Choiaella suggests that it evolved a flattened body form independently of other choiids, and was derived from earlier, conical hamptoniidlike taxa in which spicule differentiation had not yet developed. Such disordered, moderately tall sponges are known from the Hetang Biota, (new genus C, Figure 1.6). A close relationship to the Hamptoniidae is supported, however, by the lack of hexactine-based spicules in Choiaella, a feature that would be expected in a member of the basal protomonaxonid group. It should be noted that hexactines were thought initially to be present, but were later considered to be the results of monaxial spicules crossing each other (Rigby and Hou, 

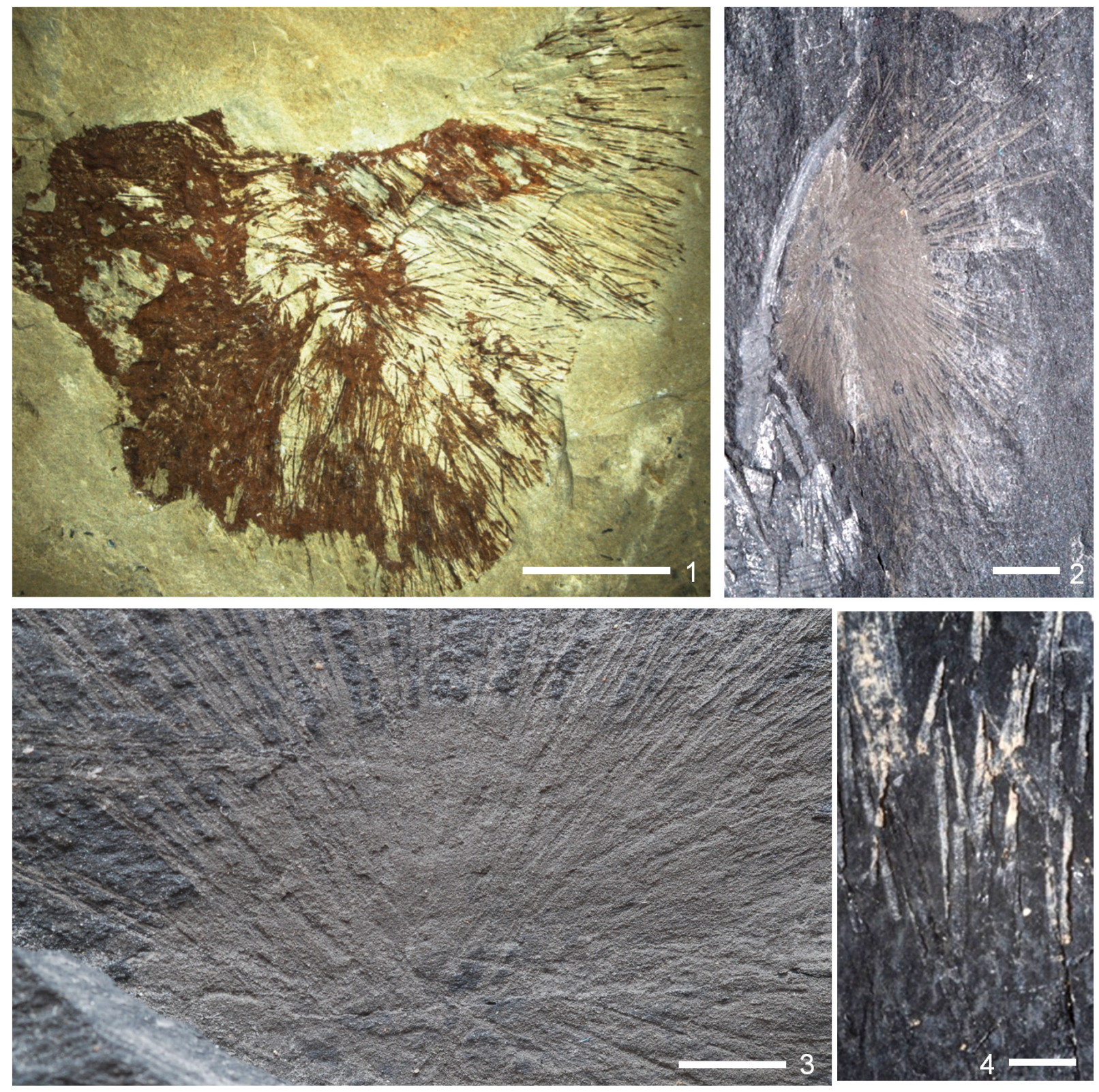

FIGURE 3. Hamptoniidae and 'Choiidae'. 1, Hamptonia bowerbanki, ROM6I9I4 from Monarch Cirque, British Columbia (ROM), with bimodal array of monaxons including relatively large, prominent spicules embedded in finer thatch; 2-3, NIGP155895 Choia sp. from the Hetang Biota; 2, overall view showing projecting monaxons; 3, magnified view of central body showing acicular coronal spicule bases (compare with Figure 4); 4, Lenica sp. NIGP154161, detail showing conical, organic-walled spicules preserved as flattened, partly pyritised moulds. Scale bars equal: 1: 10 $\mathrm{mm} ; 2$, $4: 5 \mathrm{~mm} ; 3: 2 \mathrm{~mm}$.

1995); it is possible that additional material will reestablish their presence. In addition, an undescribed Choiaella-like sponge from the Fezouata Biota appears to contain small, short-rayed hexactines (Peter Lee, personal commun., 2012).

The remaining sponges traditionally regarded as choiids (Lenica and Allantospongia) are equally problematic. Allantospongia Rigby and Hou, 1995 is very poorly known, but is probably close to Choiaella in construction, although somewhat less organised. The differences may even be partly related to partial decomposition of an originally more parallel-spiculed skeleton. Lenica, in contrast, appears to be a very large, probably conical (preserved as fan-shaped; Figure 3.4) sponge (Ivantsov et al., 2005) in which spicules can be in 
excess of $200 \mathrm{~mm}$ long. It is also characterised by an extremely robust organic outer layer to the spicules (Botting et al., 2012). Unlike in Choia, there is no clear distinction in size between disc and coronal spicules, and the spicules are in general less densely packed together.

The Choiidae, as currently defined, include three fundamental structures: Choia, ChoiaellaAllantospongia, and Lenica, which is discussed in the next section. On the basis of the substantial differences described above, we consider these groups to be only superficially similar, with a distinctive open conical to flattened body form that gives the appearance of a close relationship. The existence of phylogenetic gaps is supported by the undescribed Fezouata species that shows a similar body form but retains hexactine-based spicules (Peter Lee, personal commun., 2012; see basal protomonaxonids, above), implying substantial separation from the purely monaxonid hamptoniid lineage. The family should therefore be discontinued, with all described genera except Lenica included in a modified understanding of the Hamptoniidae, which we recommend should be recognised on the basis of dominantly longitudinal skeletal architecture, with or without the development of bimodality in spicules, but without hexactine-based spicules or echinating (projecting) prostalia. The new Fezouata Biota 'choiid' and possibly Choiaella (if hexactines are present) should be considered as basal protomonaxonids, based on their retention of hexactine-based spicules, but Choiaella is left in the Hamptoniidae pending confirmation of the presence of hexactines. The position of Lenica is uncertain based only on architecture, but the development of the scleritelike spicules indicates a position within the more derived Halichondritidae-Piraniidae group.

Halichondritidae-Piraniidae. Conical to cylindrical, often tall sponges with strong development of enlarged, projecting spicules; wall-parallel spicules typically reduced. Prostalial spicules with strongly-developed outer organic layers, and their bases poorly-defined or open. Osculum normally surrounded by pronounced fringe of marginalia.

We currently include only Halichondrites, Pirania and, questionably, Ulospongiella and Lenica in the group. The Halichondritidae are a poorly understood group of tall conical protomonaxonid sponges with a disordered, highly echinating, bimodal skeleton (Rigby, 1986a; Finks and Rigby, 2004b; Rigby and Collins, 2004). There has been uncertainty over the definition of the group because the type material (Dawson and Hinde in
Dawson,1896) was extremely poor, and the current understanding of the genus is based on more recent finds (Walcott, 1920; Rigby, 1986a; Rigby and Collins, 2004) that have been assigned to the same taxon. This paper refers to the group as they are currently understood (Finks and Rigby, 2004b), and resolution of the problems with taxonomic definition is deferred until a more complete understanding is possible. The best specimens assigned to the genus (Rigby, 1986a) are effectively a cylindrical and more disorganised version of Hamptonia, with spicule bases embedded at all points in a thin wall, and many spicules projecting outwards in addition to those aligned roughly parallel to the body wall. The sponge shows the same distinction into fine and robust monaxons, but with the latter being open-based structures.

One potentially critical aspect of evolution within this group is the morphology of the large monaxons. Normally described as probably oxeas (diactine monaxons) (Rigby, 1986a; Finks and Rigby, 2004b; Rigby and Collins, 2004), the spicules in many species do not show a clear base, even when the base is exposed. This is particularly true in Lenica (Hetang Biota, previously assigned to the Choiidae) and Choia hindei (Burgess Shale; suggested to be reassigned to Lenica by Ivantsov et al., 2005), but is also visible in Halichondrites specimens from the Burgess Shale. Closer examination reveals that in Lenica and Pirania the base of these spicules is open, and their overall form effectively conical (Figure 4.1-4.4). They also appear to be preserved as flattened reflective (Burgess Shale) or partly pyritised (Hetang Biota) films, implying an organic composition, equivalent to the organic outer layer known in certain other early sponges (Botting and Butterfield, 2005; Harvey, 2010) and modern Calcarea (Jones, 1967). A detailed analysis of Lenica material from the Hetang Biota has argued for an outer organic sheath and shown that the spicules were biminerallic, with an inner silica core and probably calcite between the silica and the outer sheath (Botting et al., 2012). Biminerallic composition may have been widespread among protomonaxonids, but the original composition is rarely demonstrable due to dissolution or replacement. Species referred to Hamptonia, Choia, and Choiaella are not known to have possessed biminerallic spicules, but this may be due either to ubiquitous taphonomic loss or to their relatively fine spicules; as yet, the composition of few Cambrian sponges have been successfully analysed, and those that have been are usually the ones with the largest spicules. 

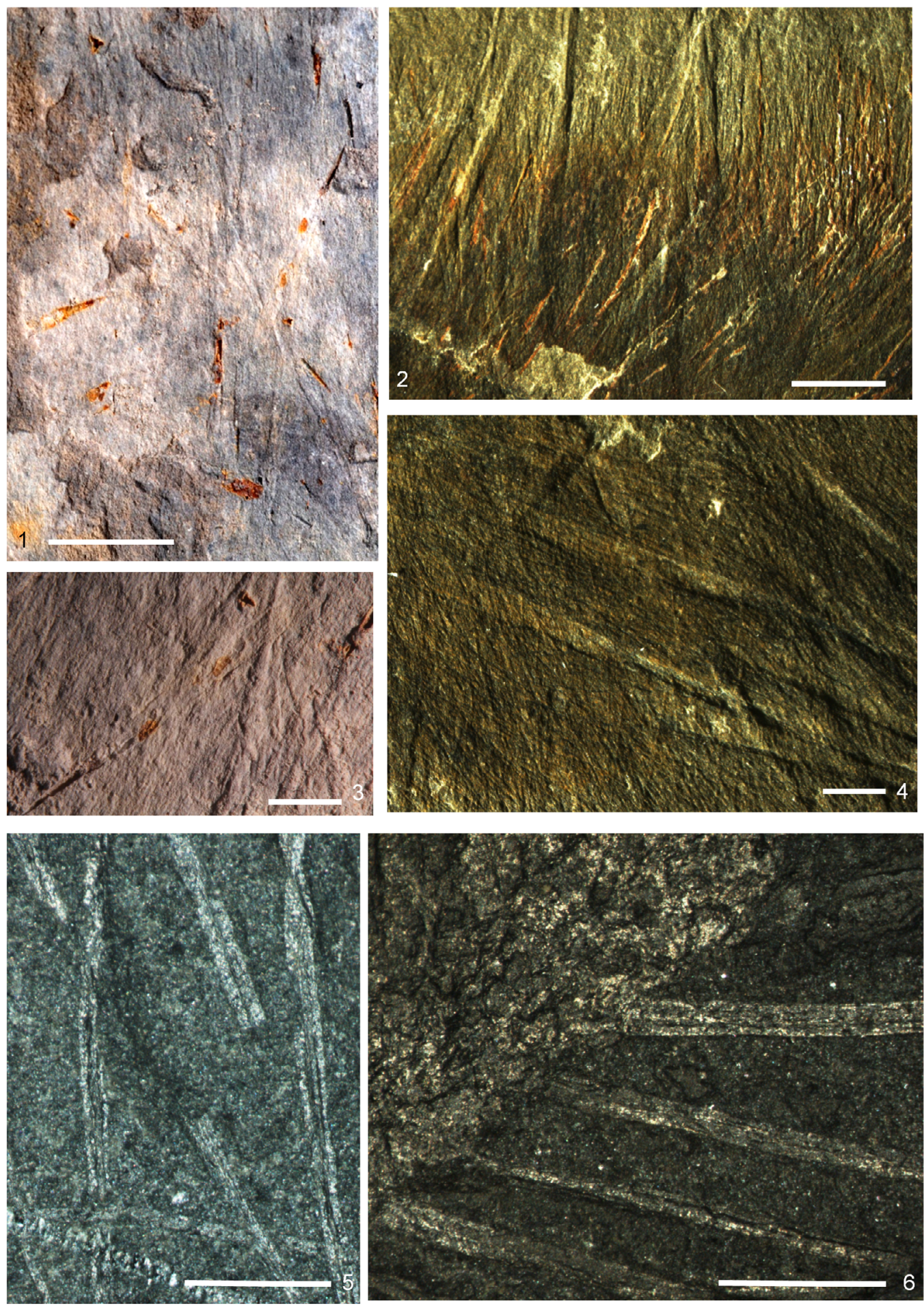

FIGURE 4. Halichondritid and piraniid sponges from early and middle Cambrian Lagerstätten. 1,3, apparently undescribed halichondritid-like sponge NIGP155896, Hetang Biota (early Cambrian, Anhui, South China); 1, view of partial specimen, showing architecture of fine monaxons and open-based, conical spicules; 3 , detail with single conical spicule; 2, 4, Choia hindei (ROM53563) from the Burgess Shale, showing bimodal spicule sizes, the flattened open bases of large spicules shown in D; 5-6 Pirania muricata; 5, ROM6I9I3, details of central parts of spicules with preserved axial regions, dissolved middle layer, and organic preservation of outer film; 6 , ROM53589, detail showing insertion of spicules into sponge wall, with poorly-defined, apparently open bases. Scale bars equal: 1-2: $5 \mathrm{~mm}$; 3, 5-6: $1 \mathrm{~mm}$; 4: 2 $\mathrm{mm}$. 
An undescribed sponge from the Hetang Biota (early Cambrian, South China; Figure 4.1) shows the open-based spicules particularly clearly, with the robust conical spicules being relatively short and broad. These spicules are partly pyritised at the closed distal end (Fig. 4.3), but not at the open end: if the spicules in life were closed at the base by an unpreserved material, the pyritisation would be expected to occur in the entire microenvironment. This specimen therefore strongly suggests that the open base of these spicules is genuine.

These modified, organic-walled spicules are developed further in the Piraniidae. Aside from Pirania, only the poorly known Moleculospina is yet assigned (questionably) to this family (Rigby, 1986a); we prefer to leave the relationships of Moleculospina open, but suspect it is closer to the Haplosclerida than to the Protomonaxonida. Pirania species are tubular (sometimes branching), with a narrow osculum, and covered by a dense radial array of fine monaxons with numerous very pronounced prostalia (traditionally regarded as styles or tylostyles; Rigby and Collins, 2004). These prostalia closely resemble those of Lenica (above) in possessing an apparently open, broad base and a thick organic outer layer (Figure 4.6). The twisting of some of these spicules (Figure 4.5) suggest that they were not entirely circular in cross-section, perhaps with the organic layer extended as fins on either side of the mineralised central part. There is also evidence for biminerallic construction resembling that of Lenica in a preserved spicular core in some specimens (Figure 4.5-4.6).

The body form of Pirania closely resembles that of Hamptonia elongata Rigby and Collins, 2004, which was described as probably intermediate between Hamptonia and Halichondrites. This species shares with Pirania auraeum Botting, 2007 a less distinct separation between the prostalia and other radiating spicules. Pirania was itself referred to the Halichondritidae by Reitner and Wörheide (2002), following Mehl-Janussen (1999); and we agree that the groups form a continuum.

Ulospongiella ancyla Rigby and Collins, 2004 possessed unique sigmoid spicules, transversely oriented in the body wall, combined with a variable number of robust monaxons resembling those of Pirania. This sponge cannot be easily related to other genera without additional material that clarifies the origins of its unique features, but the basic architecture most closely resembles that of Pirania among known taxa.

\section{Group Two Protomonaxonids}

This group consists of sponges, the spicules of which are exclusively small monaxons (typically less than $1 \mathrm{~mm}$ long, and never more than $3 \mathrm{~mm}$ ), usually in the form of oxeas but modified to dendroclones in one group. The spicules are arranged in dense tracts, often sub-longitudinal but anastomosing in two or three dimensions, and sometimes reduced to a regular reticulation of few or single spicules attached end-to-end; projecting, subradial spicules or tufts are common at the dermal surface. The tracts are presumed to have been supported by or embedded in spongin, which in some groups is exaggerated, with the reduction and eventual loss of spicules. The Hazeliidae and Vauxiidae-Anthaspidellidae are placed in this group.

Hazeliidae. Sponges with varied morphology but skeletal body wall consisting of fine oxeas, variably developed into tracts that form fine networks in two or three dimensions.

This includes the diverse species currently classified as Hazelia, together with Crumillospongia, Falospongia and Hamptoniella. Taxa are excluded if they exhibit a highly regularised and reduced reticulate skeleton with spicule apices expanded (Anthaspidellidae), or strong development of organic fibres supplanting the functional skeleton (Vauxiidae); these group are discussed below.

The Hazeliidae is the most diverse group of sponges in the Burgess Shale community, although examples are rare elsewhere in Laurentia (Rigby, 1987; Rigby et al., 1997; Johnston et al., 2009) and most genera are not yet known from other continents. The only widely distributed genus is Crumillospongia, reported from the middle Cambrian Murero Shale of Spain (García-Bellido et al., 2011) and the early Cambrian Niutitang Formation, Chengjiang Biota and Guanshan Biota of South China (Yang and Zhao, 2000; Dornbos et al., 2005; Wang et al., 2005; Hu et al., 2010). Due to the low preservation potential of the minute spicules, many of these specimens have been recognised only on the basis of the supposedly distinctive pore arrangement. This distinctiveness is questionable, as one of the specimens described by Rigby and Collins (2004, plate 17, figure 1) as Crumillospongia frondosa shows projecting spicules over the surface (Figure 5.4), and probably represents a separate, undescribed taxon. Hazeliids without parietal gaps from the South China assemblages may also not be recognisable due to the fineness of the diagnostic skeleton; the apparent absence of 

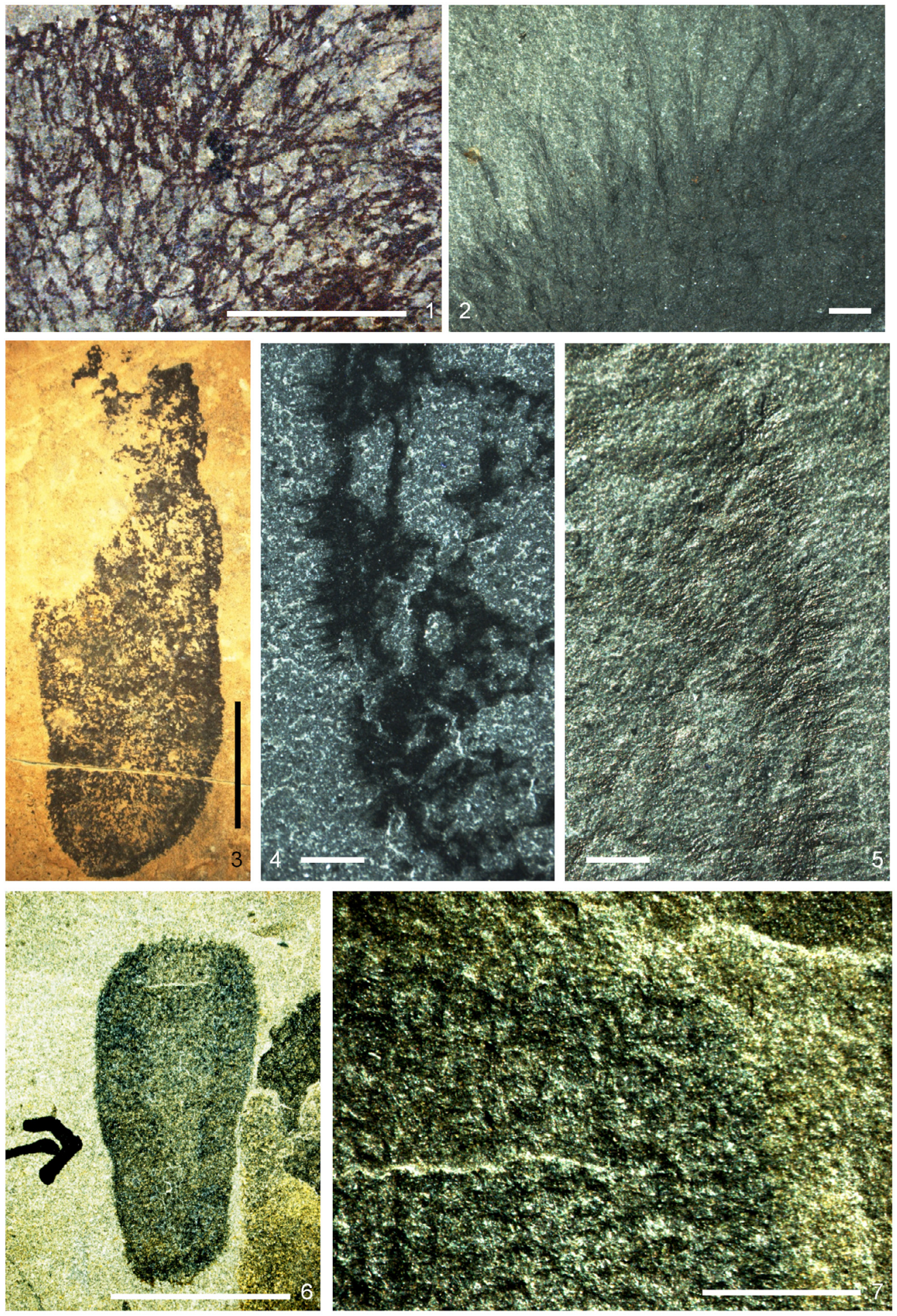

FIGURE 5. Hazeliidae from the Burgess Shale (middle Cambrian, British Columbia, Canada). 1, Hamptoniella foliata ROM44283, with sub-longitudinal array of spicule tracts and irregular cross-branching and reticulation; 2, Hazelia palmata ROM56247, distal part of large frondose specimen showing continuation of spicule tracts beyond margin; 3 , ROM61912, an undetermined hazeliid with a moderately thick, but disorganised wall and no reticulation; 4-5, ROM53578, new taxon described as Crumillospongia frondosa (Rigby and Collins, 2004) but showing echinating spicule tracts incompatible with that genus, visible in both cross-polarised (4) and low-angle light (5); 6-7, Hazelia delicatula ROM56258, with detail of upper right region (7) showing reticulate skeleton. Scale bars equal: $1,6: 5 \mathrm{~mm}$; 2, 4-5, 7: $1 \mathrm{~mm}$; 3: $10 \mathrm{~mm}$. 
Hazelia from South China should therefore be treated with caution, especially as many taxa remain unpublished and species with few visible spicules are the most difficult to describe.

All members of the family have skeletons based around bundled tracts of very small monaxons, usually aligned broadly parallel to the sponge axis but with wide local variation, leading to anastomosing and even polygonal reticulate arrays. These tracts may be two dimensional as in Crumillospongia, or variably three-dimensional, typically with the development of echinating tufts at the dermal surface. The described species of Hazelia include a progression of complexity in skeletal structure (Figure 5), including potentially important similarities to the structure of extant haplosclerids (discussed below).

There is more variation in the skeletal construction within Hazelia than there is between Hazelia and related taxa such as Hamptoniella and Falospongia, which developed specific elements of the skeleton sufficiently to appear distinct but which are fundamentally equivalent. The significant developments of the skeleton within Hazelia are based around the extension of the skeleton into three dimensions and the regularity of the architecture.

In Falospongia and Hamptoniella, the skeletal network is dominantly longitudinal and more irregularly anastomosing, producing fan-like arrays of strands as in Hamptoniella foliata (Figure 5.1). Both these genera have evolved a dominantly longitudinal tract array, and so can appear somewhat similar. The structure of Hamptoniella is threedimensional, as can be seen for example in $H$. palmata, which has a dense array of skeletal strands that project at the distal sponge margin (Figure 5.2), whereas Falospongia shows an effectively two-dimensional structure resembling Hazelia luteria or Crumillospongia. It should be noted that the structure of Hamptoniella was interpreted by Rigby and Collins (2004) as being an effectively solid sponge with numerous longitudinal canals, but restudy has shown that this is not the case.

The relatively complex architectures of Falospongia, Hamptoniella, and the more complex Hazelia species were presumably derived from simpler structures, although it is unclear whether the ancestral members of the group had regular polygonal skeletons as in $H$. conferta (discussed under Vauxiidae, below), or a more disordered tractose array. The simplest two-dimensional structure known, despite the presence of a complex array of parietal gaps, is that of Crumillospongia.
The Hazeliidae appeared in the latest early Cambrian (Rigby, 1987) in Laurentia, and by the time of the Burgess Shale was already diverse. There are, however, very few examples of earlier Cambrian sponges from Laurentia, and those from the Sirius Passet Biota are yet unstudied, so it is possible that there is a relatively deep early Cambrian history of hazeliids within Laurentia.

Vauxiidae-Anthaspidellidae. Skeletal architecture of cored spongin strands in a hexagonal-rectangular array, the fibres surrounding tracts of fine oxeas, and the tracts normally only one or two spicules wide. Skeletal mesh in many cases extended into an additional, finely-textured and less regular dermal layer.

Normally regarded as widely separated families, these are here recognised as a closely integrated group. Some lineages (Anthaspidellidae: Capsospongia and Fieldospongia) modified and strengthened the spicular component with the loss of obvious spongin fibres, and others (Vauxia) strengthened the organic component with loss of spicules.

There are several described species of Vauxia from the Burgess Shale and Utah faunas (Rigby, 1980; Rigby, 1986a; Rigby and Collins, 2004), and related but poorly known material from Greenland (Rigby, 1986b; Peel and Ineson, 2011) and South China. They all share a network of fibres in usually two connected layers, the inner one regularly polygonal, and the outer one with a finer and less regular reticulation arising from vertical strands that divide as they approach the surface. The overall architecture and polygonal nature of the inner layer is generally consistent within the genus, consisting of longitudinal rows of hexagons, frequently with the lateral angles on one or both sides suppressed so that they approach pentagons or rectangles (Figure 6.2) but adjacent rows reveal the hexagonal origin through their offset (Figure 6.4). Species are differentiated on details of the body form, branching habit, and quantitative aspects of the skeletal mesh.

In some species, notably Vauxia bellula (Walcott, 1920; Rigby, 1986a), the fibres are cored by structures preserved in relief, in contrast to the flattened organic fibres in which they are embedded (Figure 6.2-6.4). Rigby (1986a) regarded these cores as being constructed from a pith-like axial region, as is present in modern Verongida, but gave no explanation as to why they should be preserved in relief. Mineralisation of a pith region could potentially explain the structures, except that in all specimens seen in this study, the prominence 

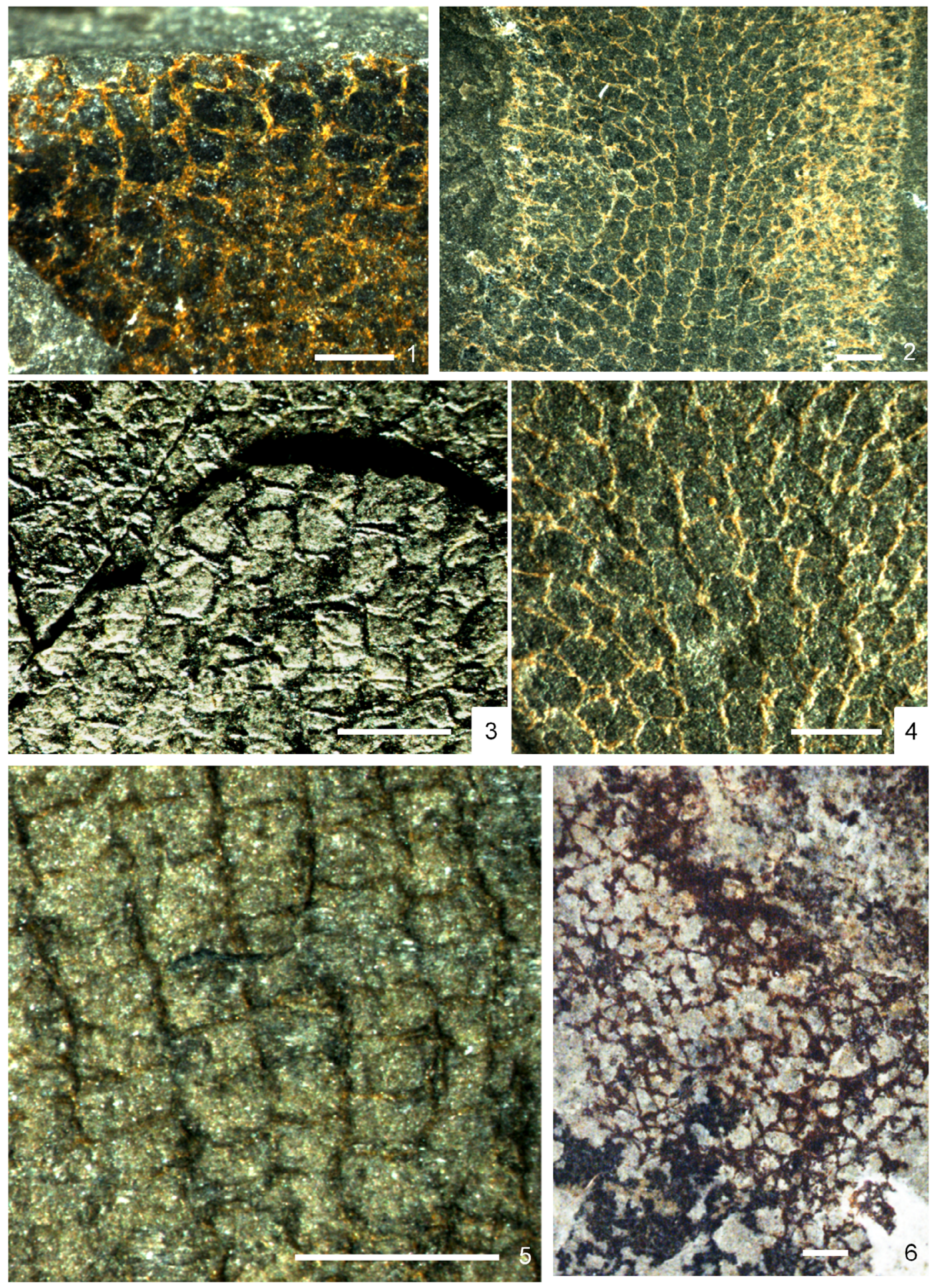

FIGURE 6. Members of the vauxiid-anthaspidellid complex, from the Burgess Shale (middle Cambrian, British Columbia, Canada). 1, detail of Hazelia conferta ROM56253, with sub-regular reticulation of primary skeleton; 2,4, Vauxia cf. bellula ROM6I 9I I, showing regular hexagonal (pseudo-rectangular) reticulation of longitudinal columns, lateral parts complicated by superposition of the dermal layer, and detail (4) showing framework composed of discrete, usually paired and sometimes misaligned spicules; 3, Vauxia bellula ROM 56243; 5, Fieldospongia bellilineata ROM53602, showing regular arrangement of single and double monaxons to form hexagonal (sub-rectangular) reticulation; 6 , undescribed fragment of anthaspidellid lithistid on same slab as ROM44283, with more complex skeletal architecture. Scale bar equals $1 \mathrm{~mm}$. 
of these elements is effectively constant across the specimen; if crystallisation of, for example, pyrite was occurring inside restricted microenvironments, some degree of variation should be expected across the skeleton.

High-magnification examination of these fibre cores in Vauxia bellula (Figure 6.3-6.4) has also revealed that they are not continuous structures as in the primary meshwork, but discrete elements that join at points, are sometimes misaligned, and in some cases are composed of two such elements adjacent to each other. These structures are best interpreted, both taphonomically and morphologically, as small monaxon spicules, identical to those of Hazelia and Crumillospongia. A close relationship is confirmed by Hazelia conferta, which is intermediate between a complex-walled hazeliid structure, and a vauxiid with cored fibres; the spicule strands are thin, often composed of only a few subparallel monaxons, and the inner wall reticulation is virtually identical to that of Vauxia, with longitudinal rows of hexagonal to rectangular cells (Figure 6.1). There is thus a morphological continuum between the more complex-walled Hazelia species to Vauxia, via $H$. conferta and V. bellula. The spicule strands of typical Hazelia were almost certainly enveloped by smaller quantities of organic skeletal material, which allowed the structure to be preserved intact as frequently as it has been.

The Cambrian Anthaspidellidae are structurally very close to the Vauxiidae. The arrangement of spicules in Fieldospongia bellilineata Walcott, 1920 is identical to that of Vauxia bellula (Figure 6.5). The same reticulation is created by apparently identical short monaxons, arranged either singly or in sub-parallel pairs, and with similar levels of variability from the idealised pattern. The most important difference appears to be that the spicules are not embedded within an obvious organic fibre in Fieldospongia. Given the extreme rarity of the species, and its absence from horizons with abundant, high-fidelity soft-tissue preservation, it is possible that the species is a taphomorph of Vauxia bellula. However, the presence of the definitive anthaspidellid Capsospongia argues for a genuine difference, as Capsospongia has continued the same trend to produce a more idealised but otherwise identical reticulation of small monaxons (see Rigby and Collins, 2004, plate 21, figures 3,5), in which spicules are almost invariably arranged singly and meet at points. The primary difference distinguishing Capsospongia is the terminal expansions of these spicules to form dendroclones. This allowed the construction of a more robust framework, but the skeleton is otherwise virtually identical to that of Fieldospongia, which in turn closely resembles Vauxia bellula. These taxa therefore combine to form another lineage allied to the hazeliid-vauxiid group, indicating that the phylogenetic origins of several major groups lie within one complex of Cambrian sponges.

An undescribed specimen from the Burgess Shale (Figure 6.6) illustrates a more derived anthaspidellid architecture, in which the regular sub-rectangular organisation has been replaced by more typically lithistid, near-isodictyal array with triangular and hexagonal mesh spaces. There can be little doubt that this organisation is phylogenetically continuous with the later Palaeozoic Anthaspidellidae.

\section{DISCUSSION}

\section{Construction of Hypothesised Phylogenetic Scenario}

The observations and comparisons above have enabled a hypothetical, characterised phylogenetic framework to be developed (Figure 7). Although doubtless incorrect in some aspects, we hope that our provision of character-based definitions of each branch means that it can act as a basis for future modification. Preliminary attempts to perform a cladistic analysis led to unstable trees that were extremely sensitive to changes in character choice and coding. This is probably due to there being too many gaps in the fossil record, such that known taxa are often morphologically disparate, and too few characters that are demonstrably useful. A reasoned approach as has been previously employed, but with a much more rigorous, character-based framework, offers the best framework for interpretation of early sponge evolution at this stage.

The two groups are treated separately here, as they appear to be architecturally distinct, although it is possible that they are linked by unknown intermediate forms. We have used skeletal architecture and spicule morphology as the main criteria, and the presented topology minimises convergent loss or acquisition of characters. We have polarised the tree by the presence of hexactines in the group described as basal protomonaxonids, which also occur earlier in the fossil record than most other lineages. It is possible that certain characters are convergently derived, but these may in the future become recognisable through attempts to integrate additional taxa into the framework. 


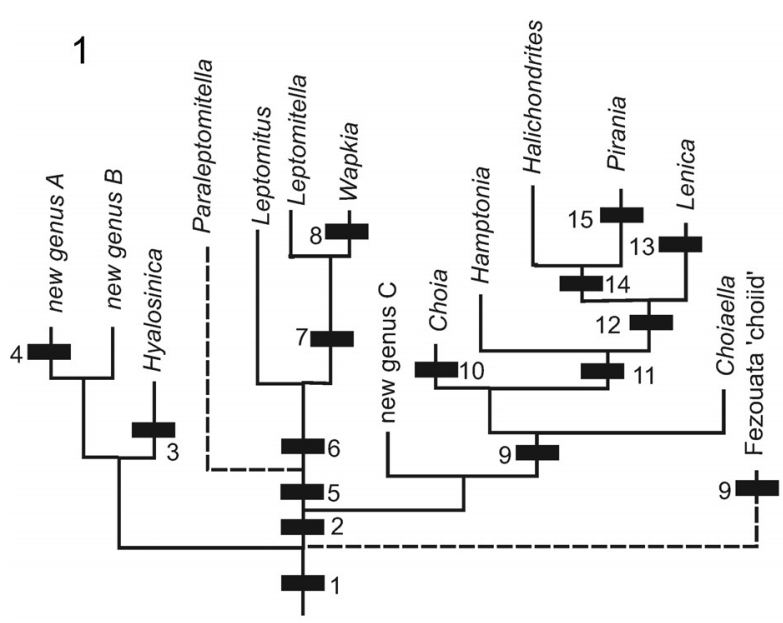

1. conical growth form, with longitudinal monaxons and short-rayed hexacts

2. loss of hexactines

3. regular helical monaxons

4. loss of monaxons; hexact rays reduced to stubs

5. transverse monaxons

6. longitudinal monaxons bundled

7. bundled transverse monaxons; some plumose arrays

8. plumose arrays dominant

9. open conical body form

10. flattened body form; coronal spicules

11. bimodal monaxon array; conical body form

12. thickened organic sheath of major spicules

13. spicules enlarged; fan-like body form

14. inclined prostalia developed; tall conical body form

15. minor spicules reduced; major spicules developed into organic-walled prostalial sclerites

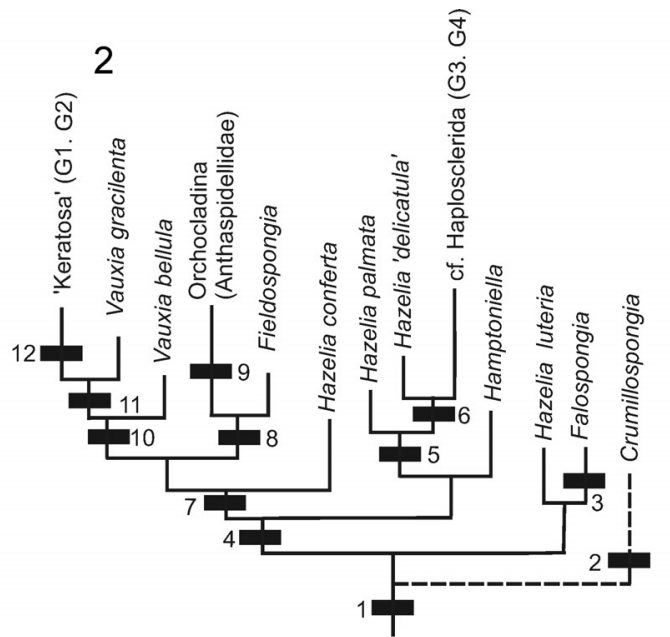

1. two-dimensional tracts of small oxeas forming thin wall

2. parietal gaps in developed in globose body wall

3. longitudinal strands strongly developed

4. echinating spicules projecting out from tracts

5. wall with -three-dimensional, irregular reticulation

6. Exaggeration of three-dimensional structure forming radial plumes; irregular body form in Haplosclerida

7. spicule tracts reduced to 2-3 spicules wide and arrangec in sub-hexagonal mesh

8. tracts reduced to single spicules

9. monaxons transformed to dendroclones

10. spicules embedded in obvious organic strands;

skeleton extended to form add finely reticulate dermal layer

11. spicules lost; organic skeleton only

12. increased three-dimensional complexity of organic skeleton

FIGURE 7. Phylogenetic hypothesis for the protomonaxonids, divided into two major groups: 1, large-spiculed taxa, including links to basal, hexactine-bearing sponges; 2, small-spiculed taxa with relationships to modern demosponge lineages. New genera A, B, and C are described briefly in the text. This reconstruction includes most of the genera described from Cambrian deposits, but a few poorly-understood or potentially problematic taxa are excluded. Vertical axis represents evolution; no scale of time or morphology is implied.

In Figure 7.1, we have assumed a single loss of hexactine-based spicules (character 2). However, this requires multiple convergence of a flattened ('choiid') body plan, which we consider likely given the structural differences between genera. This requires that taxa with flattened morphology fall into the paraphyletic basal region of the Piraniidae + Hamptoniidae. The placement of problematic taxa such as Ulospongiella Rigby and Collins, 2004 and Allantospongia Rigby and Hou, 1995 has been discussed in relevant sections above.

The relationship of the Leptomitidae to other protomonaxonids is questionable, but the recognition of a coherent family is supported by several characters (Figure 7.1). The diversity of basal protomonaxonids (Hyalosinica and allies) in the Hetang Biota is rapidly increasing with additional collections, suggesting the basal part of our tree may have been much more extensive than it appears here, with only a few major lineages becoming successful enough to leave a prominent fossil record. The position of new genus $C$ is poorly constrained, but it appears to be close to the base of Leptomitidae, or to Choiaella. We have chosen to place it on the lineage leading to Choiaella (Figure 7.1) based on their similarity in the disordered, longitudinal thatch of monaxons. This evolutionary scenario is illustrated schematically in Figure 8.1. Regarding the origin of basal protomonaxonids, one possible scenario is that initiation of dominantly monaxon spiculation arose from extension of anchoring basalia. In the Cambrian genus Diagoniella, for example, which is normally assigned to the Reticulosa, large monaxial basalia appear to be positioned largely within the body wall and project a little way into the sediment (Rigby and Collins, 2004). Multiplication of these spicules could 


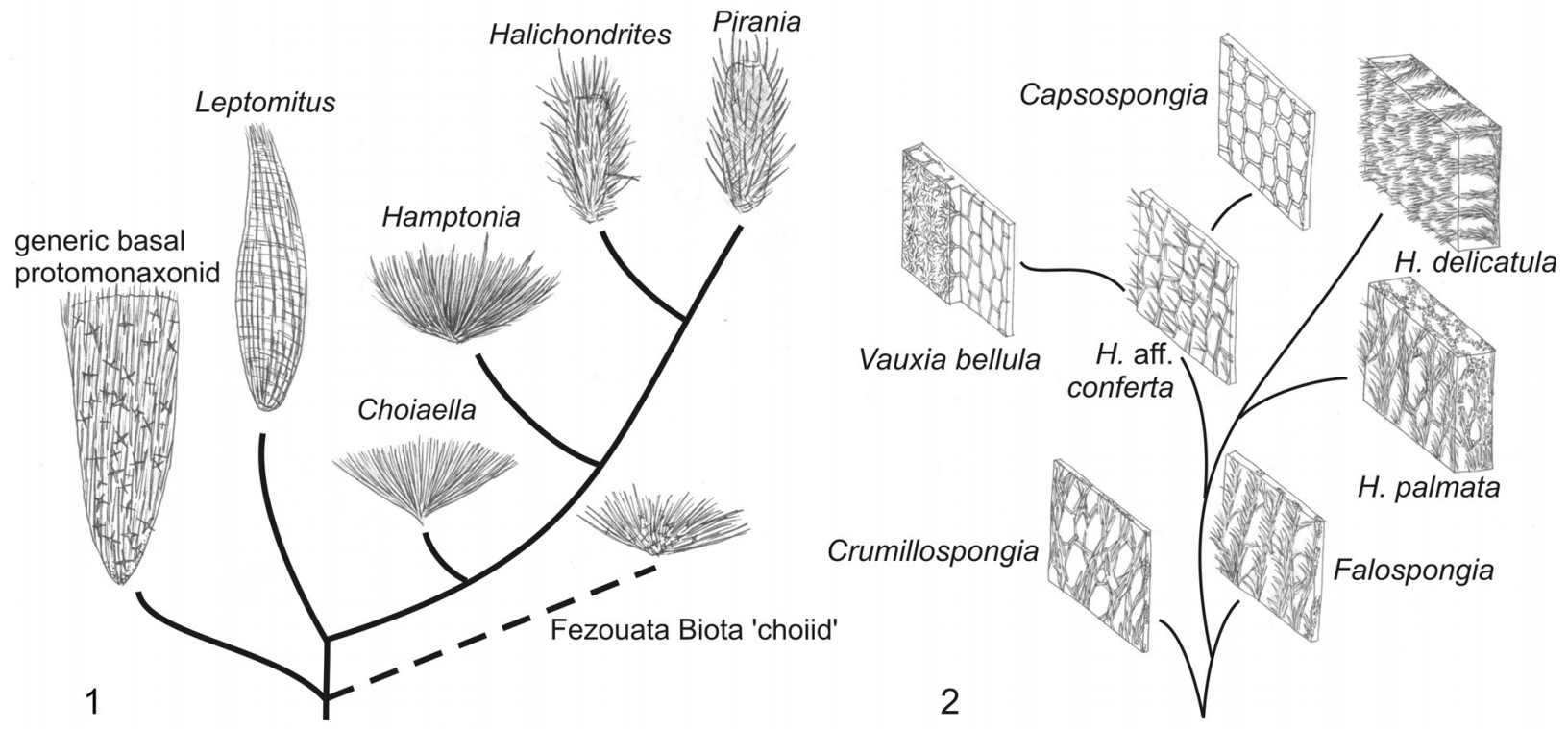

FIGURE 8. Schematic illustration showing primary skeletal development in protomonaxonids, referring to the most fundamental changes described in Figure 7. 1, Group One (refers to Figure 7.1); 2, Group Two (refers to Figure 7.2).

have rapidly led to a body wall supported by dominantly longitudinal monaxon spicules.

Group Two (Figures 7.2, 8.2) is less diverse but in some ways more complex, and the relationships to extant lineages are discussed in detail in the next section. Formulating a viable phylogeny requires two basic assumptions: that apparently close similarity of fossils to particular modern lineages is meaningful, and that the group in general progressed from a simple skeletal architecture to a more complex arrangement. These assumptions result in the basal taxa being represented by Crumillospongia. The only reticulosans with abundant monaxons are taxa such as Cyathophycus, with an inner wall layer of fine monaxons, similar to that of hazeliids (as discussed by Botting, 2003). However, there is no consensus on the origin of the group, and if they are instead derived from Group One protomonaxonids then assuming a Cyathophycus-like sponges as the ancestor could incorrectly polarise the character distributions. We have therefore made the explicit assumption that the simple, disorganised structure of Crumillospongia represents the basal condition for the group, primarily on the basis that the more complex or regularised structures seen in other branches lead to close comparisons with later and extant lineages.

The structure of Crumillospongia is most similar to the two-dimensional walls of Hazelia luteria and Falospongia, despite the lack of obvious parietal gaps. Falospongia is placed slightly higher in the tree, but the only character separating them is the strong development of longitudinal linear strands, which occurs (probably convergently) in some later-branching genera. We have assumed that modification of body form, or the development of linearised or reticulate tracts from less regular ones, are simpler changes than the development of three-dimensional skeletal organisation. One outcome of this is that Hazelia becomes a very inclusive (or polyphyletic) genus, and all the genera within the Hazeliidae will be reclarified as part of a taxonomic review by JPB and others.

The previously defined families Vauxiidae and Anthaspidellidae are supported by several specific characters, but form a continuum with certain members of the Hazeliidae, as shown (Figures 7.2, 8.2). The origins and relationships of these two families are discussed in detail below.

\section{Relationships of Group Two Protomonaxonids to Extant Demosponges}

Establishing the phylogeny of extant demosponges has proved surprisingly difficult (BouryEsnault, 2006). It should be possible to reconstruct at least some likely ancestral character states from extant taxa, but morphological studies of modern sponges have been ambiguous in their implications. Uriz and Maldonado (1995) studied ornament in polyaxon and monaxon spicules, and suggested tentatively that monaxons may have arisen by suppression of rays in polyaxons. How- 
ever, studies combining morphological, genetic, and biochemical data have found widespread contradictions, indicating that morphologically dissimilar modern taxa can be closely related, and that similar taxa need not be (Erpenbeck et al., 2006; Erpenbeck and Wörheide, 2007 and references therein). While this shows that morphology-based studies can be problematic, this is a problem related specifically to the heavily diversified modern demosponge fauna, where the difficulty is in recognising which characters are most informative. The character-mapping retrospectively conducted by Borchiellini et al. (2004) on their molecular phylogeny showed a few reversals but otherwise consistent patterns, suggesting that even in the most difficult living groups the morphology can be reliable once the critical features are identified.

Recent molecular phylogenies (e.g., Borchiellini et al., 2004; Erpenbeck and Wörheide, 2007; Kober and Nichols, 2007; Redmond et al., 2007; Erpenbeck et al., 2009) consistently show the basal groups to be those including aspiculate demosponges (Keratosa and Myxospongiaea of Borchiellini et al., 2004). Borchiellini et al. (2004) assessed their trees for morphological characters including spicule morphology, and found that among spiculate taxa, diactines were basal, with tetraxonids in their analysis occurring in a single branch. Within one major derived clade, monactines and diactines appear to have been evolutionarily interchangeable. The same broad outline has been recovered by the other studies listed above, and this basic topology appears to be stable. Molecular phylogenetics therefore indicates that the basal demosponges were either aspicular or possessed diactine monaxons.

This restudy of protomonaxonids indicates that several groups of extant demosponges appear to be derived from a closely allied group of protomonaxonids and vauxiids. Assuming that that vauxiids do indeed represent basal "keratose" demosponges, then these, together with Vauxia bellula, Fieldospongia, and Capsospongia, indicate a close relationship to the Anthaspidellidae, which would be phylogenetically distant from other 'lithistid' lineages. The origins of this group appear to lie with taxa such as the fundamentally similar Hazelia conferta, which in turn shows strong structural continuity with other Hazelia species. The basic hazeliid architecture, consisting of dense, irregular strands of small monaxons, is consistent with that of the extant Haplosclerida, and an ancestral relationship to this group must form a null hypothesis.
In particular, certain groups such as the Callyspongiidae display spicules embedded in spongin fibres, as exaggerated in such taxa as Vauxia bellula but presumed to be present throughout the hazeliids in order to support their skeletal structure. By extrapolation of the trends outlined in Figure 8.2, taxa with a pronounced radial skeletal array (such as $\mathrm{H}$. delicatula) could have rapidly evolved to a body form closely resembling that of many modern monaxon-based demosponges. This scenario for the basal demosponge groups agrees in both topology and character distribution with those derived from molecular phylogenetics (e.g., Borchiellini et al., 2004). Most notably, there is agreement in the existence of a deep node separating the largely keratosan demosponges from the dominantly spiculate taxa, and in the primitive status of diactine monaxons (oxeas) among the latter group. Borchiellini et al. (2004) could not assess whether the basal demosponges had spiculate or organic skeletons, but the palaeontological evidence for spicules extending well into the stem groups of living classes (especially within Silicea; Botting and Muir, in press) implies that spicules were lost in the keratosan lineages. The basal monaxonid demosponge group appears to be the Haplosclerida (Borchiellini et al., 2004; BouryEsnault, 2006), which includes probably the simplest architectures among living groups. The fundamental skeleton of Haplosclerida is composed of reticulating networks of oxeas, either bonded by spongin or enclosed within fibres (Boury-Esnault, 2006) - a fundamentally similar organisation to that seen in the Hazeliidae.

More derived demosponge lineages presumably arose through modification and diversification of the proto-haplosclerid lineage. The axinellid architecture has been cited as being traceable to particular Palaeozoic sponges (e.g., Finks, 1967, 1970; Reitner and Wörheide, 2002), but recognising homologous skeletal structures is difficult. Based on the presence of seemingly advanced spicules, including microscleres (Kozur et al., 1996) in Early Palaeozoic limestones, the origins of more derived taxa such as Borchiellini et al.'s (2004) G4 grouping may have been in carbonate shelf or shallow-water environments, where their delicate skeletons of small spicules are generally unlikely to have been preserved. This is supported by the presence of the apparent tetraxonid Ivantsovia in calcareous sediments of the early Cambrian Sinsk Biota (Ivantsov et al., 2005). 


\section{CONCLUSIONS}

Restudy of previously described material, combined with observations of new material from Canada and South China, has provided a range of new insights into the nature and relationships of sponges assigned to the Protomonaxonida (Finks and Rigby, 2004b). These new observations include:

- Hyalosinica-like sponges with numerous small, short-rayed hexactine spicules;

- presence of hexactines in Choia-like sponges;

- recognition of near-identical architecture in superficially distinct, conical, and flattened protomonaxonids;

- recognition of open-based, conical spicules in Pirania, Halichondrites, Lenica, and allied sponges;

- presence of spicules within skeletal strands of Vauxia bellula; and

- identical organisation of skeleton of Hazelia conferta with Vauxia species and Cambrian anthaspidellids such as Capsospongia.

These new data have allowed a clear separation of two major groups of protomonaxonid sponges in Cambrian faunas. One group possessed large (often several centimetre-long) monaxons in longitudinal or radiating arrays, and the other had minute monaxons embedded in strands of organic tissue, typically forming dense tracts with an overall longitudinal and/or radial orientation. The former group is shown to have been derived from hexactine-bearing ancestors, and the latter is argued to have given rise to "keratose" sponges, anthaspidellids, and probably also basal examples of Haplosclerida, together with the remaining demosponge lineages. The relationship between the two groups, however, is currently unclear; they may be phylogenetically linked, although no clear intermediates are yet known, but it is also possible that the Protomonaxonida as currently defined is polyphyletic as well as paraphyletic.

The most satisfying result of this study is the congruence between molecular and palaeontological results regarding basal demosponges. The nature of taxa at the deep nodes within phylogenies can be constrained by studies of modern organisms, but not described in any detail; palaeontological results can offer direct observational evidence of these nodes. Until now, early sponge phylogeny has been intractable, but the combined developments in these two fields are starting to clarify at least some aspects of the topology, and the natures of the common ancestors.

\section{ACKNOWLEDGEMENTS}

Many thanks to J.-B. Caron for providing images for Figure 2.6, and to him, P. Fenton, and L. O'Brien for providing access to specimens housed at the ROM. Thanks also to Y. Xunlai for arranging access to the Hetang Biota localities in Anhui, China, as well as specimens in his care, and to P. Lee for providing photographs and discussion of his Fezouata Biota specimens. The manuscript has been further improved by the suggestions of two anonymous reviewers. The work is partly supported by the Project-Oriented Hundred Talents Programme (grant no. KZCX2-YW-BR-23) to JPL. JPB's research has been funded by the National Science Foundation of China Research Fellowship for International Young Scientists (grant no. 41150110152), and LAM is receiving funding from China Postdoctoral Science Foundation (grant no. 20110490136).

\section{REFERENCES}

Bengtson, S. and Vinther, J. 2006. The role of Eiffelia in early sponge evolution. Geological Society of America Abstracts with Programs, 38:304.

Bengtson, S., Conway Morris, S., Cooper, B., Jell, P.A., and Runnegar, B. 1990. Early Cambrian fossils from South Australia. Memoir of the Association of Australasian Paleontologists, 9:1-364.

Bergquist, P.R. 1978. Sponges. University of California Press, Berkeley and Los Angeles.

Borchiellini, C., Chombard, C., Manuel, M., Alivon, E., Vacelet, J., and Boury-Esnault, N. 2004. Molecular phylogeny of Demospongiae: Implications for classification and scenarios of character evolution. Molecular Phylogenetics and Evolution, 32:823-837.

Botting, J.P. 2003. Cyathophycus and the origin of demosponges. Lethaia, 36:335-344.

Botting, J.P. 2007. 'Cambrian' demosponges in the Ordovician of Morocco: insights into the early evolutionary history of sponges. Geobios 40:737-748.

Botting, J.P. 2012. Reassessment of the problematic Burgess Shale sponge Takakkawia lineata Walcott, 1920. Canadian Journal of Earth Sciences, 49:10871095.

Botting, J.P. and Butterfield, N.J. 2005. Reconstructing basal sponge relationships using the Burgess Shale fossil Eiffellia. Proceedings of the National Academy of Sciences, 102: 1554-1559.

Botting, J.P. and Muir, L.A. in press. Spicule structure and affinities of the Ordovician hexactinellid-like sponge Cyathophycus loydelli (Llanfawr Mudstones Lagerstätte, Wales). Lethaia. 
Botting, J.P. and Zhang, Y. 2013. A new leptomitid-like sponge from the Early Ordovician of China with heteractinid spicules. Bulletin of Geosciences, 88:207217.

Botting, J.P., Muir, L.A., Xiao, S., Li, X.-F. and Lin, J.-P. 2012. Evidence for spicule homology in calcareous and siliceous sponges: biminerallic spicules in Lenica sp. (Porifera; ?Protomonaxonida) of early Cambrian age $(535-520 \mathrm{Ma})$ from South China. Lethaia, 45:463-475.

Boury-Esnault, N. 2006. Systematics and evolution of Demospongiae. Canadian Journal of Zoology, 84:205-224.

Brusca, R.C. and Brusca, G.J. 2003. The Invertebrates, (second edition). Sinauer, Sunderland, Massachusetts.

Carrera, M. and Botting, J.P. 2008. Evolutionary history of Cambrian spicular sponges: implications for the Cambrian evolutionary fauna. Palaios, 23:124-128.

Chen, J., Hou, X., and Li, G. 1990. New Lower Cambrian demosponges - Quadrolaminiella gen. nov. from Chengiiang, Yunnan. Acta Palaeontologica Sinica, 29, 402-413. [In Chinese, English summary.]

Chen, J., Hou, X., and Lu, H. 1989. Lower Cambrian leptomitids (Demospongea), Chengiiang, Yunnan. Acta Palaeontologica Sinica, 28:17-31. [In Chinese, English summary.]

Dawson, J.W. 1896. Additional notes on fossil sponges and other organic remains from the Quebec Group of Little Métis on the lower St. Lawrence; with notes on some of the specimens by Dr. G.J. Hinde. Transactions of the Royal Society of Canada, 44:91-121.

Debrenne, F. and Reitner, J. 2001. Sponges, cnidarians, and ctenophores, p. 301-325. In Zhuravlev, A.Yu. and Riding, R. (eds), The Ecology of the Cambrian Radiation. Columbia University Press, New York.

De Laubenfels, M.W. 1955. Porifera, p. E21-E112. In Moore, R.C. (ed.), Treatise on Invertebrate Paleontology, Part E. Geological Society of America and University of Kansas Press, Lawrence, 1-122.

De Laubenfels, M.W. 1958. Nomenclature of Porifera, especially concerning the so-called "Glass Sponges" or Hyalospongea. Journal of Palaeontology, 32:611616.

Dornbos, S.Q., Bottjer, D.J., and Chen, J. 2005. Palaeoecology of benthic metazoans in the early Cambrian Maotianshan Shale biota and the Middle Cambrian Burgess Shale biota: evidence for the Cambrian substrate revolution. Palaeogeography, Palaeoclimatology, Palaeoecology, 220:47-67.

Erpenbeck, D. and Wörheide, G. 2007. On the molecular phylogeny of sponges (Porifera). In Zhang, Z.-Q. and Shear, W.A. (eds.), Linnaeus Tercentenary: Progress in Invertebrate Taxonomy. Zootaxa, 1668:107-126.
Erpenbeck, D., Breeuwer, J.A.J., Parra-Valendia, F.J., and van Soest, R.M.W. 2006. Speculation with spiculation? - Three independent gene fragments and biochemical characters versus morphology in demosponge higher classification. Molecular Phylogenetics and Evolution, 38:293-305.

Erpenbeck, D., Voigt, O., Wörheide, G., and Lavrov, D.V. 2009. The mitochondrial genomes of sponges provide evidence for multiple invasions by Repetitive Hairpin-forming Elements (RHE). BME Genomics, 10(591):14 pp.

Erwin, D.H., Laflamme, M., Tweedt, S.M., Sperling, E.A., Pisani, D., and Peterson, K.J. 2011. The Cambrian conundrum: early divergence and later ecological success in the early history of animals. Science, 334:1091-1097.

Finks, R.M. 1967. The structure of Saccaspongia laxata Bassler (Ordovician) and the phylogeny of the Demospongea. Journal of Paleontology, 41:1137-1149.

Finks, R.M. 1970. The evolution and ecologic history of sponges during Palaeozoic times. Symposia of the Zoological Society of London, 25:3-22.

Finks, R.M. 2003. Paleozoic Demospongea: morphology and phylogeny, p. E63-E80. In Finks, R.M., Reid, R.E.H., and Rigby, J.K. (eds.), Treatise on Invertebrate Paleontology, Part E, Porifera, Revised, Volume 2. Geological Society of America and University of Kansas Press, Boulder, Colorado, and Lawrence, Kansas, 1-349.

Finks, R.M. and Rigby, J.K. 2004a. Palaeozoic hexactinellid sponges, p. E320-E448. In Finks, R.M., Reid, R.E.H., and Rigby, J.K. (eds.), Treatise on Invertebrate Paleontology, Part E, Porifera, Revised, Volume 3. Geological Society of America and University of Kansas Press, Boulder, Colorado, and Lawrence, Kansas, 1-872.

Finks, R.M. and Rigby, J.K. 2004b. Paleozoic Demosponges, p. 9-171. In Finks, R.M., Reid, R.E.H., and Rigby, J.K. (eds.), Treatise on Invertebrate Paleontology, Part E, Porifera, Revised, Volume 3. Geological Society of America and University of Kansas Press, Boulder, Colorado, and Lawrence, Kansas, 1-872.

Finks, R.M., Reid, R.E.H., and Rigby, J.K. (eds.) 2003. Treatise on Invertebrate Paleontology, Part E, Porifera, Revised, Volume 2. Geological Society of America and University of Kansas Press, Boulder, Colorado, and Lawrence, Kansas, 1-349.

García-Bellido, D.C., Dies Álvarez, M.E., Gámez Vintaned, J.A., Liñán, E., and Gozalo, R. 2011. First report of Crumillospongia (Demospongea) from the Cambrian of Europe (Murero Biota, Spain). Bulletin of Geosciences, 86:641-650.

Gruber, G. and Reitner, J. 1991. Isolierte Mikro- und Megaskleren von Porifera aus dem Untercampen von Höver (Norddeutschland) und Bemerkungen zur Phylogenie der Geodiidae (Demospongiae). Berliner geowissenschaftliche Abhandlungen, 134:107-117. 
Harvey, T.H.P. 2010. Carbonaceous preservation of Cambrian hexactinellid sponge spicules. Biology Letters, 6:834-837.

$\mathrm{Hu}$, ShiXue, Zhu, MaoYan, Steiner, M., Luo, HuiLin, Zhao, FengChen, and Liu, Q. 2010. Biodiversity and taphonomy of the Early Cambrian Guanshan biota, eastern Yunnan. Science China, Earth Sciences, 53:1765-1773.

Ivantsov, A.Yu., Zhuravlev, A.Yu., Krasilov, V.A., Leguta, A.V., Mel'nikova, L.M., Urbanek, A., Ushatinskaya, G.T., and Malakhovskaya, Ya.E. 2005. Unikal'nye sinskie mestonakhozhdeniya rannekembriiskikh organizmov, sibirskaya platforma. Trudy paleontologicheskogo instituta, 284:1-143. [In Russian]

Johnston, K.J., Johnston, P.A., and Powell, W.G. 2009. A new, Middle Cambrian, Burgess Shale-type biota, Bolaspidella Zone, Chancellor Basin, southeastern British Columbia. Palaeogeography, Palaeoclimatology, Palaeoecology, 277:106-126.

Jones, W.C. 1967. Sheath and axial filament of calcareous sponge spicules. Nature, 214:365-368.

Kober, K.M. and Nichols, S.A. 2007. On the phylogenetic relationships of hadromerid and poecilosclerid sponges. Journal of the Marine Biological Association of the United Kingdom, 87:15851598.

Kozur, H.W., Mostler, H., and Repetski, J. 1996. 'Modern' siliceous sponges from the lowermost Ordovician (early Ibexian - early Tremadocian), Windfall Formation of the Antelope Range, Eureka County, Nevada, U.S.A. Geologische-Paläontologische Mitteilungen, Innsbruck, 21:201-221.

Li, C.-W., Chen, J., and Hua, T.-E. 1998. Precambrian sponges with cellular structures. Science, 279:879882.

Mehl-Janussen, D. 1999. Die frühe Evolution der Porifera. Münchner Geowissenschaftlichen Abhandlungen, 37:1-72.

Peel, J.S. and Ineson, J.R. 2011. The Sirius Passet Lagerstätte (early Cambrian) of North Greenland. Palaeontographica Canadiana, 31:109-118.

Philippe, H., Derelle, R., Lopez, P., Pick, K., Borchiellini, C., Boury-Esnault, N., Vacelet, J., Renard, E., Houliston, E., Quéinnec, E., Da Silva, C., Wincker, P., Le Guyader, H., Leys, S., Jackson, D.J., Schreiber, F., Erpenbeck, D., Morganstern, B., Wörheide, G., and Manuel, M. 2009. Phylogenomics revives traditional views on deep animal relationships. Current Biology, 19:1-7.

Pisera, A. 2006. Palaeontology of sponges - a review. Canadian Journal of Zoology, 84:242-261.

Redmond N.E., van Soest, R.W.M., Kelly, M., Raleigh, J., Travers S.A.A., and McCormack, G P. 2007. Reassessment of the classification of the Order Haplosclerida (Class Demospongiae, Phylum Porifera) using 18S rRNA gene sequence data. Molecular Phylogenetics and Evolution, 43:344-352.
Reid, R.E.H. 1963. A classification of the Demospongia. Neues Jahrbuch für Geologie und Paläontologie, Monatshefte, 4:196-207.

Reid, R.E.H. 1968. Microscleres in demosponge classification. The University of Kansas Palaeontological Contributions, 35:1-37.

Reid, R.E.H. 1970. Tetraxons and demosponge phylogeny. Symposia of the Zoological Society of London, 25:63-89.

Reiswig, H.M. 1971. The axial symmetry of sponge spicules and its phylogenetic significance. Cahiers de Biologie Marine, 12:505-514.

Reitner, J. and Mehl, D. 1995. Early Paleozoic diversification of sponges: new data and evidences. Geologisch-Paläontologische Mitteilungen Innsbruck, 20:335-347.

Reitner, J. and Mehl, D. 1996. Monophyly of the Porifera. Verhandlungen des naturwissenschaftliche Vereis in Hamburg, 36:5-32.

Reitner, J. and Wörheide, G. 2002. Non-lithistid fossil demospongiae - origins of their palaeobiodiversity and highlights in history of preservation, p. 52-70. In Hooper, J.N.A. and van Soest, R.M.W. (eds.), Systema Porifera: A Guide to the Classification of Sponges. Kluwer Academic/Plenum Publishers, New York.

Rigby, J.K. 1980. The new Middle Cambrian sponge Vauxia magna from the Spence Shale of Northern Utah and taxonomic position of the Vauxiidae. Journal of Paleontology, 54:234-240.

Rigby, J.K. 1983. Sponges of the Middle Cambrian Marjum Limestone from the House Range and Drum Mountains of Western Millard County, Utah. Journal of Paleontology, 57:240-270.

Rigby, J.K. 1986a. Sponges of the Burgess Shale (Middle Cambrian) British Columbia. Palaeontographica Canadiana Monograph, 2:1-105.

Rigby, J.K. 1986b. Cambrian and Silurian sponges from North Greenland. Rapport - Groenlands Geologiske Undersoegelse, 132:51-63.

Rigby, J.K. 1987. Early Cambrian sponges from Vermont and Pennsylvania, the only ones described from North America. Journal of Paleontology, 61:451-461.

Rigby, J.K. and Collins, D. 2004. Sponges of the Middle Cambrian Burgess and Stephen Shale Formations, British Columbia. Royal Ontario Museum Contributions in Science, 1:1-164.

Rigby, J.K. and Hou, X. 1995. Lower Cambrian demosponges and hexactinellid sponges from Yunnan, China. Journal of Paleontology, 69:1009-1019.

Rigby, J.K., Gutiérrez-Marco, J.C., Robardet, M., and Piçarra, J.M. 1997. First articulated Silurian sponges from the Iberian Peninsula (Spain and Portugal). Journal of Paleontology, 71:554-563.

Sethmann, I. and Wörheide, G. 2008. Structure and composition of calcareous sponge spicules: a review and comparison to structurally related biominerals. Micron, 39:209-228. 
Sperling, E.A., Robinson, J.M., Pisani, D., and Peterson, K.J. 2010. Where's the glass? Biomarkers, molecular clocks and microRNAs suggest a 200-Myr missing Precambrian fossil record of siliceous sponge spicules. Geobiology, 8:24-36.

Steiner, M., Mehl, D., Reitner, J., and Erdtmann, B.-D. 1993. Oldest entirely preserved sponges and other fossils from the Lowermost Cambrian and a new facies reconstruction of the Yangtze platform (China). Berliner geowissenschaftliche Abhandlungen, 9:293329.

Uriz, M.J. 2006. Mineral skeletogenesis in sponges. Canadian Journal of Zoology, 84:322-356.

Uriz, M.J. and Maldonado, M. 1995. A reconsideration of the relationship between polyaxonid and monaxonid spicules in Demospongiae: new data from the genera Crambe and Discorhabdella (Porifera). Biological Journal of the Linnean Society, 55:1-15.

Van Kempen, T.M.G. 1985. On the oldest tetraxon megascleres, p. 9-16. In Rützler, K. (ed.), New Perspectives in Sponge Biology. Smithsonian Institution Press, Washington, D.C.

Van Roy, P., Orr, P.J., Botting, J.P., Muir, L.A., Vinther, J., Lefebvre, B., El Hariri, K., and Briggs, D.E.G. 2010. Ordovician faunas of Burgess Shale type. Nature, 465:215-218.
Walcott, C.D. 1920. Middle Cambrian spongiae. Cambrian geology and paleontology IV. Smithsonian Miscellaneous Collections, 67:261-364.

Wang, Ping-li, Zhao, Yuan-long, Yang, Xing-lian, and Yang, Rong-Jun 2005. Crumillospomgia biporosa (sponge) from the Early Cambrian Niutitang Biota in Guizhou Province. Acta Micropalaeontologica Sinica, 22:196-201.

Xiao, Shuhai, Hu, Jie, Yuan, Xunlai, Parsley, R.L., and Cao, Ruiji 2005. Articulated sponges from the Lower Cambrian Hetang Formation in southern Anhui, South China: their age and implications for the early evolution of sponges. Palaeogeography, Palaeoclimatology, Palaeoecology, 220:89-117.

Yang, X. and Zhao, Y. 2000. Sponges of the Lower Cambrian Niutitang Formation Biota in Zunyi, Guizhou, China. Journal of Guizhou University of Technology, 29:30-36.

Zhao, Yuan-long, Steiner, M., Yang, Rui-dong, Erdtmann, B.-D., Guo, Qing-jun, Zhou, Z., and Wallis, E. 1999. Discovery and significance of the early metazoan biotas from the Lower Cambrian Niutitang Formation, Zunyi, Guizhou, China. Acta Palaeontologica Sinica, 38(supp.):132-146. 